

\section{EXCHANGE}
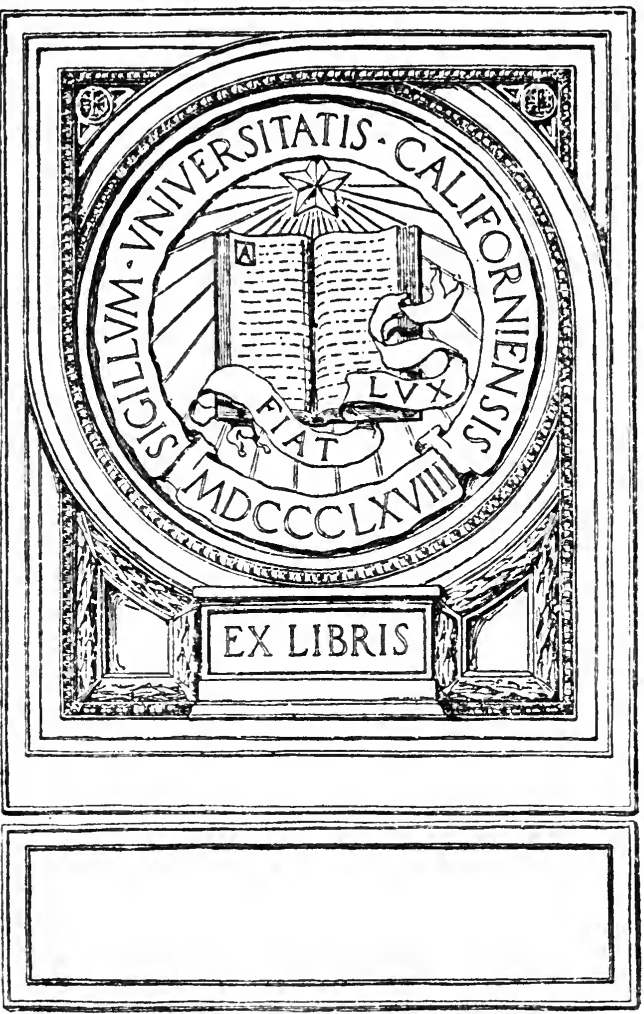


\title{
The Doctrine of Formal Discipline
}

\author{
BY \\ C. K. LYANS
}

\begin{abstract}
A DISSERTATION SUBMITTED TO THE FACULTY OF CLARK UNIVERSITY, WORCESTER, MASS., IN PARTIAL FULFILMENT OF THE REQUIREMENTS FOR THE DEGREE OF DOCTOR OF PHILOSOPHY, AND ACCEPTED ON THE RECOMMENDATION OF WILLIAM H. BURNHAM
\end{abstract}

Reprinted from the PEDAGogical SEMINARY

September, 1914, Vol XXI, pp. 343-393 



\title{
The Doctrine of Formal Discipline
}

BY

\author{
C. K. LYANS
}

\begin{abstract}
A DISSERTATION SUBMITTED TO THE FACULTY OF CLARK UNIVERSITY, WORCESTER, MASS., IN PARTIAL FULFILMENT OF THE REQUIREMENTS FOR THE DEGREE OF DOCTOR OF PHILOSOPHY, AND ACCEPTED ON THE RECOMMENDATION OF WILLIAM H. BURNHAM
\end{abstract}

Reprinted from the Pedagogical Seminary September, 1914, Vol XXI, pp. 343-393 
$\angle B 1059$

$-9$

$$
\therefore
$$




\title{
THE DOCTRINE OF FORMAL DISCIPLINE
}

\author{
By C. K. Lyans, Clark University
}

An attempt to discuss the doctrine of formal discipline finds itself balked at the very outset by the question: "What is formal discipline?" The literature on the subject shows a great variety of definitions, but one division between writers comes out with special clearness: those who attack the doctrine have a very different definition of it than have those who defend it. The result is that the opposing sides in the controversy have failed to clash: dispute has tended to magnify their apparent differences, and has minimised their real points of agreement-and there has been great confusion.

To clear the field, I shall take first the definition of the doctrine as seen by its foes, and as seen by its friends, and seek from a comparison of the two views to determine what the controversy has really been about.

(I) As seen by its foes: Two things have especially occupied the attention of those who attack formal disciplinethey have seen in it a doctrine that training is transferable, and have found its basis in the faculty psychology. Also, they have seen it as a doctrine having much to do with the selection of studies, and little to do with the pedagogy of instruction: it is to them the weapon of the formalist, used to defend subjects that have lost practical utility. Henderson defines it as meaning "the supposed effect of study upon the mind, entirely apart from the content of what is learned." Monroe reiterates the definition, but amplifies it much further. According to him, the doctrine teaches that " a particular activity or experience, especially of an intellectual character, if well selected, produces a power or ability out of all proportion to the expenditure of energy therein: a power that will be serviceable in most dissimilar experiences or activities, that will be available in every situation, that will be applicable to the solution of problems presented by any subject, however remote from the one furnishing the occasion for the original disciplinary experience." ( $16, \mathrm{p}$. 508.) His discussion, again, is followed by Graves (ro, vol. 2, p. 309). Since all agree, however, in citing Locke as the 
first writer who clearly formulated the disciplinary conception for education, especially in his "Conduct of the Understanding," we have in that work a basis for criticism of such definitions as that just quoted from Monroe. Therefore, before touching on the views of contemporary defenders of formal discipline, I shall give a brief analysis of Locke's doctrines :

(2) As seen by its friends, Locke's "Conduct of the Understanding" contains, though in a rather unsystematic way, some treatment of nearly every factor of the learning process recognized by the most recent psychologists-even to the influence of the attitude or 'set.' We may note the doctrines most significant for our purpose under five heads:

(a) Reasoning. Good reasoning, says Locke, demands a large, sound, roundabout sense, "conversation with many sorts of men, contact with many sorts of books and notions. If one would reason soundly, he should "take a taste of every sort of knowledge: it is certainly very useful and necessary to form the mind."

(b) Improvability of functions. Under this heading comes a statement of what Thorndike calls the laws of use and disuse: Of disuse, "The great number is of those whom the ill habit of never exerting their thoughts has disabled." (I, p. 207.) Of use, "We are born with faculties and powers capable of almost anything, such at least as would carry us farther than can easily be imagined, but it is only the exercise of those powers which gives us ability and skill in anything." (I, p. I90.) He emphasizes, however, the specific character of training-which is the more significant because there was no controversy over the question of specific vs. general training, in his day, and therefore any but a very careful thinker or writer would have been pretty sure to use generalizations which would seem to ignore the specific nature of training, no matter how thoroughly he himself believed that improvement of functions does not transfer. Never having encountered any other view, he might quite naturally take for granted that no other view was held, and feel no need of going into particulars. But Locke did go into particulars. He points out that we learn to dance only by practice in dancing; to think by thinking; and, indeed, that even such a seemingly innate quality as ready wit in conversation is very much the result of practice, "to be raised to that pitch only by repeated actions." (I, p. I9I.)

(c) Transfer. Yet Locke does teach that training may transfer, although he has emphasized its original, specific character. This comes out strongest in the case of mathe- 
matics, where he even uses the term "transfer." $\mathrm{He}$ says children should be taught mathematics so that "having got the way of reasoning, which that study necessarily brings the mind to, they might be able to transfer it to other parts of knowledge as they have occasion." But he sees clearly that this transfer may work for evil as well as good: "A metaphysician will bring plowing and gardening immediately to abstract notions, the history of nature shall signify nothing to him." And again, "Some men have so used their heads to mathematical figures, that giving a preference to the methods of that science, they introduce lines and diagrams into their study of divinity or politic inquiries, as if nothing would be known without them." (I, p. 22I.) It is precisely because too wide a transfer of one type of mental habit ensues from a one-sided education, that Locke insists on a many-sided education. He insists-to repeat a quotation already given above-that one should "take a taste of every sort of knowledge; it is certainly very useful and necessary to form the mind." $\mathrm{He}$ warns against the uselessness and danger of having only a smattering of everything, and points out the necessity of mastering one's own particular subject, but for one who heeds these warnings, "the end and use of a little insight in those facts of knowledge which are not a man's proper business, is to accustom our minds to all sorts of ideas, and the proper ways of examining their habitudes and relations. This gives the mind a freedom, and the exercising the understanding in the several ways of inquiry and reasoning which the most skilful have made use of, teaches the mind sagacity and wariness, and a suppleness to apply itself more closely and dexterously to the bents and turns of the matter in all its researches. Besides, this universal taste of all the sciences, with an indifferency before the mind is possessed with any one in particular, and grown in love and admiration of what is made its darling, will prevent another evil very commonly to be observed in those who have from the beginning been seasoned only by one part of knowledge. Let a man be given up to the contemplation of one sort of knowledge, and that will become everything. The mind will take such a tincture from a familiarity with that object, that everything else, how remote soever, will be brought under the same view." (I, p. 215.)

(d) Attitude. The quotations already given are sufficient to illustrate Locke's position concerning the attitude or "set" and many more quotations could be given, for his doctrine on this point pervades and colors his whole treatise. $\mathrm{He}$ recognizes that one pursuing a given subject develops an 
attitude appropriate to that subject; that one whose education, being confined to one subject, has provided him with but one attitude, will apply that attitude to all subjects, from not having learned a better mode of attack; and therefore it is highly desirable to provide in education, through the study of a variety of subjects, as rich a repertory as possible of "sets," so that in dealing with new material-or for that matter, even for the sake of dealing more effectively with the old-the mind may "apply itself more closely and dexterously to the bents and turns of the matter in all its researches."

(e) $\mathrm{He}$ insists on the importance for thinking of close attention, pointing out that habits of hasty and desultory work result from its neglect.

This plainly does not square with Monroe's description of the disciplinary conception in education. According to Monroe, that conception teaches that (I) education in one wellselected subject, rather than in many, is best; (2) there is unlimited transfer of training; (3) education in the right subject defies the law of conservation of energy, getting thoroughly disproportionate results: whereas we have seen that Locke, whom Monroe takes as the best representative of this conception; (I) teaches that education should be many-sided; (2) holds a doctrine of transfer differing little from the "identical elements" theory so generally held to-day: and if we take in his doctrine concerning the attitude, Locke's position is wholly reconcilable with that taken by Thorndike, perhaps the leading opponent of the disciplinary idea, in his most recent work. (3) Anything claiming disproportionate results for some particular subject is nowhere to be found in Locke's work.

Turning to Locke's other educational work, "Some Thoughts Concerning Education," we find in his remarks on subjects of study, a corroboration of this interpretation of his doctrine; for his approval or disapproval of various subjects rests almost entirely on practical grounds. Especially noticeable is his discussion of the two subjects around which controversy since his time has raged most violentlyLatin grammar and mathematics. He disapproves the manner in which Latin grammar was used in his day, on the ground that the language could be better taught without teaching grammar at the beginning; and the Latin language itself is included in his course of study simply because "it is absolutely necessary for a gentleman "-holding then a place that French has since largely usurped, in England. Speaking of mathematics, he limits the amount of geometry that should 
be taught, to six books of Euclid, giving as his reason: "I am in some doubt, whether more to a man of business (i.e., man of affairs) be necessary or useful; at least if he have a genius or inclination to it, being entered so far by his tutor, he will be able to go on of himself." ( 1, p. I49). There are a few remarks, in the discussion of subjects to be taught, that have a slight disciplinary coloring, but the impression one gains from reading that part of Locke's work, is that he is rather too indifferent not only to disciplinary but even to cultural values, in laying out his course of study.

The fact is, Locke's real contribution is in his emphasis on the improvability of functions-precisely the thing for which Thorndike contends in his "Psychology of Learning"- -and his theory is not at all at variance with the doctrine that transfer is a matter of "identical elements." On points of detail there are differences, but they are traceable wholly to differences in analysis, not to contradictions in theory. They only raise the questions: what elements are identical? how are we to decide upon the identity of elements?-questions for which we have nowhere a decisive answer yet. It is further to be noted, Locke never taught that "the process of learning, and not the thing learned, is of importance." That introduces a false opposition-his emphasis was on the point that the thing learned-including the process of learning-is important primarily because of its effect on the mind and character; and mere unassimilated memorial learning is worthless. Monroe recognizes this when he says: "One of the most striking of Locke's positions, as well as one of the soundest of them, is the clear distinction he ever holds in mind between education and instruction." ( 1, p. 5I5.) This distinction has become a commonplace of educational thought to-day, thanks to the work of Locke, Rousseau, Herbart, and a host of lesser lights, but it was far from a commonplace in the $I 7$ th century-and even with $u s$, it has penetrated but a very little way into the schools.

When we turn to contemporary writers, we naturally find more stress laid on the so-called formal side of education, since this is the point against which the opposition has directed its attack. Wendell stresses the importance in education of developing concentration or will-power, saying that hard work of any sort can develop "increasingly and lastingly muscular power of voluntary attention." (I2, p. 3I.) Münsterberg argues that in the effort to learn any activity, "the development is specific-the formal training of the will is general." But even the "specific character of the training must not be exaggerated. . . . By training for baseball, we secure general 
alertness in our motor responses." $\mathrm{He}$ further insists that (I) since every mental function can really be developed, "one side of mental life must not be crippled in the interest of others, as long as general education is in question" and (2) it is of the first importance that the voluntary attention be developed. Our education tends to neglect this, and so makes for superficiality. (I2, p. 34-5.) All the other writers who take disciplinary standpoint also emphasize this, that will-power and voluntary attention can and should be developed by education. Judd goes more into detail concerning disciplinary possibilities in the following passage: "We have been in the habit of saying that this or that kind of knowledge is valuable, and we have not really meant this or that kind of knowledge, but this or that subject-matter. I believe it is time for us to take an entirely different view of what is meant by the term kinds of knowledge. The ability to reason independently, the ability to retain the essentials and neglect the non-essentials, the ability to carry on certain types of inquiry in any subject-matter, all these forms of ability are more important than the ability to reproduce a body of particular information. The meaning of this last contention may be made somewhat clearer by saying that what we need in our examination of the high-school course of study is a complete restatement of the values of these courses in terms of the mental habits which are cultivated as distinguished from the information which is gained. We are just at the beginning of a period of study of the effects of education." (12, pp. 39-40.)

In these writers, again, we see that the stress is on improvability of functions, as distinguished from, but not necessarily apart from, the subject-matter through which the improvement is effected. As a matter of fact,--though none of the writers quoted has paid much attention to this pointthe subject-matter is part of the process of learning, to be taken into account when we estimate the improvement of a function: we apply our knowledge, not mere formal mental powers, to new problems-but that knowledge, to be applicable, must have been assimilated, organized, worked over into something that looks very much like a formal mental ability. "Mathematical ability," for example, is a knowledge of mathematical facts and principles which has become so much a part of oneself that he uses it as naturally as he would use sight and touch. Even "power of observation" involves the possession of facts available for comparison, and of principles-which are also facts - to guide the comparison; as well as an understanding, to be gained only by experience, 
of the resources and limitations of the human organism, and of the best methods for attacking the problem to be faced. From one point of view, all this is simply knowledge: from another point of view it is pure mental power.

The second point especially stressed by those who defend the disciplinary ideal, is that the power of voluntary attention, acquired in the strenuous pursuit of any subject, is generally applicable to all affairs of life. But this is only holding that the voluntary attention which keeps a man at work on mathematics is identical with the voluntary attention that keeps him at work on a case at law, or a problem of business administration. Thus, whether or not the holders of the views just quoted accept the doctrine that all transfer is explained by the presence of identical elements in the activity from which and the activity to which the transfer occurs-and most of them, I believe, do accept it-at any rate, their contentions can perfectly well be stated in terms of that doctrine. Indeed, if we read any claim that a certain subject supplies a transferable training, we find it devoted almost entirely to pointing out elements that are in the opinion of its advocate common to that subject and certain other subjects, or certain of life's activities. The defender of Latin grammar and translation work points out the demand which his subject makes upon powers of observation, the mathematician stresses the training of reason; both have much to say about the development of voluntary attention. But by the mode of their argument, they furnish common ground for discussion with their opponents. Prove that the observation which the one talks about, the reasoning power that concerns the other, and the voluntary attention which seems so important to both, are not identical with the activities that bear the same name in other parts of life, and their contention falls to the ground. On the other hand, grant that there is a real identity under the identity of name, and their opponents must grant that training in those activities may transfer, at least. I say " may transfer," because while by this theory all transfer is of identical elements, yet this need not concede that training in identical elements always transfers. Experience gives good reason to believe that it does not. The problem for us to investigate, then, is: "What are identical elements, and what principles control the transfer of training in them?"

\section{Experimental Studies}

Owing chiefly, no doubt, to the fact that satisfactory methods for comprehensive investigation of higher mental processes have not yet been devised, the experimental data on transfer 
are almost wholly confined to tests of what we may call peripheral functions, involving very little of the higher powers of observation and reasoning. Therefore experimental results prove nothing, unless by analogy, about the existence or possibility of transfer in precisely those parts of our mental life where it would be most important. In general, there have been two kinds of studies: (I) studies of transferred improvement of memory; (2) studies in the transfer of sensory or sensory-motor skill. Each of these kinds calls for some general observations, after which I shall discuss in detail a few typical experiments.

I. In the field of memory, any physiological explanation of that function would justify us in expecting to find absolutely no transfer of training. When memory was looked on as a sort of psychic reservoir, into which we dumped facts until we wanted them again, it was quite conceivable that use or training could enlarge the capacity of that reservoir; but when we conceive of memory as merely the tendency of a neurone to retain an impression that has been stamped upon it, the only possible effect of repetition would be to stamp that particular impression deeper, and it is not easy to see how the process would make the neurones constitutionally more receptive or more tenacious of other impressions, no matter how similar in content to the one through which the training was received. This objection holds, no matter which of the current views of memory we take. The only conceivable physiological correlate of a direct improvement of memory, is a change in the actual constitution of a neurone or group of neurones, quite apart from the increased sensitiveness of the neurone or neurones to the stimuli representing the subjectmatter which furnished the original training. Any direct improvement of memory as a function, is a case of real transfer, even though it be from the learning of one list of nonsensesyllables to the learning of another. Not only is memory not a faculty; it is not even a group of faculties: there are as many memories as there are things learned; every new thing learned is a new memory. Memory is simply a property of nerve substance, and to change this property would change the substance-unless we want to postulate a psychic element of memory which may change without a corresponding physiological change. But perhaps memory does improve, and the constitution of the neurones does change as an effect of training: I am not concerned either to affirm or to deny such a change, but only to point out that if there is actual improvement of memory through training, it can only be explained as accomplished in that way, and if that occurs we 
have a case of not transfer, but "spread" of training, irreducible to the functioning of identical elements. For practical pedagogy, I believe this is a matter of small importance; we have every reason to think that the amount possible of direct improvement of memory, if any at all, is very slight. Far the greater part of all gain in memorial efficiency is more satisfactorily explained as resulting from improvements in the technique of memorizing: finding advantageous devices of grouping and rhythm, improved methods of applying the attention, ways of invoking the aid of association, and in a general way, getting a better understanding-mostly subconscious, to be sure-of the properties of the nervous substance with which memorizing is so predominantly concerned.

The physiological conception of memory has crowded out the conception of memory as a unit faculty, or as a group of faculties, and so makes it impossible that we should speak of any general training of memory, or of any considerable amount of specific training. But at the same time, it gives us a new and sounder basis for? doctrine of general training in memorial technique. If memory is not a faculty functioning as a unit, yet it has a homogeneous physical basis, for we have no reason to suppose that the nervous substance of different parts of the brain obeys different laws. Consequently, so far as improving the technique of memorizing consists in discovering better ways of applying the principles which describe the behavior of nervous substances, just so far is the technique an identical element in all memorial work, and just so far can it function as such. None, I believe, of these general principles is separated out in memorial work from more special adaptations determined by the subjectmatter in which the work is done, but a glance at some of the facts concerning the behavior of memory will serve to show the presence of these underlying laws: (a) The influence of the task and the attitude (Aufgabe and Einstellung). In actual practice, the task and the attitude are different things when one is learning nonsense-syllables from what they are when he is learning poetry; but in both cases, the task of learning so as to reproduce gets a different result from the task of learning so as to recognize the right order of the words. The "set" to remember for five minutes gets a different result from that brought by the "set" to remember for a week. (b) Finding optimal groupings and rhythms, and optimal length of working periods, of intervals between sittings, etc. These vary immensely, from the comparatively short periods required by nonsense-syllables, to the long periods that are favorable with a subject-matter of a kind that 
is interesting, familiar, and significant to the learner; but at the bottom in all cases lies the fact that it takes a little time to raise the function to its highest efficiency, and then a certain amount of work is sufficient to bring on the fatigue that reduces efficiency to a fraction of what it is when the function is fresh. There is good reason to suppose that this length of endurance is a constant for any individual, given uniform conditions of health and general bodily efficiency; and that we can work longer at significant material not because the neurones can stand more work of that sort, but because the significance of the material gives any one neurone or group of neurones less to do, spreads the same amount of actual memorial work over a longer period, and allows breathingspells between. (c) The use of association as an aid to memory. This of course dwindles to a minimum in the case of nonsense-syllables and of any unfamiliar material. To invoke the aid of association, there must be some knowledge in the mind with which associations may be formed: thus the later stages of learning a foreign language become much more efficient than the beginnings, because the basis for associations has been built up. But our interest at present is only in the physiological principle on which the helpfulness of associations for memory work rests. To establish an association with a given impression is equivalent to lowering its threshold. Without the presence of the association, the only stimulus available to reproduce the thing learned is a direct act of will: only an impression of a certain strength can respond to that stimulus-in other words, the threshold of response to a simple act of will is comparatively high. But given the aid of an established association, we have a more adequate stimulus, capable of rousing to response a weaker impression-the threshold of response has been lowered. And the greater the number of associations, the lower the threshold for the given impression becomes, and the less deeply does it need to be stamped in.

This is sufficient to illustrate my point: it is my purpose here only to point out that when we conceive of memory as a function or property of nerve-substance, we destroy the old idea of a general training of memory, but we must also infer in the place of the old idea, a new conclusion, that there are certain laws of learning, based on the behavior of nerve-substance, which are as general as the nervesubstance itself, and therefore function as identical elements in all memory-work, and furnish a medium for transfer of training. It might be added, anticipating what I shall develop more fully later, that the actual amount of transfer 
becomes much greater if the functioning of these laws is brought to consciousness, either by good teaching or by the intelligence of the learner himself; but I believe there is always and inevitably some transfer, until the limit of improvability is reached, though the transfer may be obscured or even negatived by mal-adjustment to the new subjectmatter in which evidence of transfer may be sought.

Many of the facts about transfer of training in memory are clearly brought out in Fracker's study of the problem, which is one of the best that we have. Preliminary tests were given in memory for (I) poetry, (2) the order of four shades of gray, (3) the order of nine tones of different intensities, (4) the order of nine shades of gray, (5) the order of four tones-the major chord, (6) the order of nine geometrical figures, (7) the order of nine two-place numbers, (8) the extent of arm movement. Tests number $2,3,4$, and 5 were given by a method which the author describes in the case of the four grays as follows: "The stimulator was arranged to expose each of the four gray disks for one-half second, an interval of one-half second being allowed between each exposure. . . After the four grays were exposed, a blank remained before the observer for four seconds, then another arrangement of the four grays was given and another blank exposed. When the second blank appeared, the observer responded, giving aloud the order of the first group of four grays. After the third group had been exposed, he responded to the order of the second group, and so on through the series. In responding to the order of the four grays, the observer called the darkest gray, 4 ; the next lighter, 3 ; the next lighter, 2; and the lightest, I." In the tests of nine tones, only four intensities were used, and arranged into groups of nine: for the nine grays, the four shades employed in experiment (2) were used. After the records of the test series had been taken, a training series was taken, using the four tones of experiment (3), and the method just described. Thus the training series was wholly identical in method with the series in the four grays, differing only in the use of tone-intensities instead of shades of a color.

It was found in the course of the training that all but two of the observers recognized a peculiar imagery, out of which a sort of mnemonic method was built. It is interesting to notice that none of them tried to improve their direct memory of the four tones, but all immediately translated the order of the group of tones into terms of position in space, of the serial names " 4213 ," etc., or some other form of representative imagery. This is certainly a case of calling an easier 
type of imagery to the aid of a more difficult: it would be interesting to inquire if it was also partly due to a halfunconscious effort to enlist the aid of association. But the important thing for our problem is that we have here in the training series itself the development of what might be called a manufactured transfer. With every one of the observers who recognized a distinct method of remembering, the real training was not at all in memory for the order of four intensities of tone, but in memory for something quite different; and the four tones were only treated as symbols designating the order in which these artificial images were to be arranged. One observer had a system closely related to the content of the tests, for he imaged the loudest tone as close to his ear, the softest as placed some distance off, and the other two in intermediate positions; but another had a purely visual system, made up of different-sized dots arranged in a vertical line. There is certainly no identity between black dots and tones, nor can it be supposed that these dissimilar images function in identical neurones, since no one holds that the visual centers and the auditory centers in the brain coincide: the only real identity is found in the two abstractions of "difference in size" and "arrangement in serial order," which were common to the dots and the tones-that is instead of transference through identical elements, we have transference through community of an abstraction, which is transference by analogy. Such a method is naturally applicable wherever the analogy holds good, provided that no condition is arbitrarily introduced that interferes with the smooth working of the method, as in the case of the four tones different in pitch, where the tones were called "Do, Me, Sol, Do-2," in the responses, instead of being named, " $1,2,3,4$."

How far this transference by analogy can be applied depends on the intelligence of the individual; on his ability to discover analogies. How far it will be applied depends again on his intelligence, his resourcefulness in devising new methods, his ability to recognize the limits of economy in transference. One observer may struggle along trying to apply his method by forced analogy, in situations to which it is not at all suited, while his more intelligent neighbor, recognizing that his method is wasteful in the new situation, will abandon it for a better method, even at some temporary loss in efficiency. Fracker's results illustrate both these points: that there is gain in transference by analogy, and that there is loss if the transference is carried too far. The former point, as I have shown, appears even in the results of the training series: it appears again in the final test series. Those who 
had developed a definite method in the training series, both improved most in the training, and showed the greatest gain in the final tests. Of the final tests, the four grays, nine tones, nine grays, and four tones could be handled by the methods developed in the training series, but the use of names instead of numbers to designate the four tones interfered very seriously with the application of this method to it, as several of the observers testified. The other three of the final tests to which the methods used in the training series could be applied, show in some cases a greater gain than was made in the training series-the training apparently transferred with more than hundred-per-cent efficiency. That there should be no loss of efficiency in the transfer need cause no surprise, for none of the observers was really training himself to remember the order of four tones differing in intensity. They all took the tones as symbols, possessing an obvious serial order, and trained themselves in remembering some sort of images in the order designated by these symbols. Any other set of equally understandable symbols would do just as well, as these experiments show.

The result with the test series of four tones is an interesting illustration of the tyranny of method. It was natural that stimuli so notoriously difficult to image distinctly as differences in intensity of sound, should be translated into other terms, but where the subject-matter is made up of differences in pitch, and such easy differences as the intervals of the major chord, it is unlikely that all of the observers were incapable of learning to work from direct imagery of the sounds, for anyone who can carry a simple tune in his head has sufficiently good auditory imagery to succeed with it. One did try it, but found that the notes tended to fuse into a chord-an unusual experience, surely, in the field of auditory imagery. The others all applied their previously formed methods-unsuccessfully, as I have already noticed, because names were used instead of numbers-and found this, which, for one of even moderate auditory imagery, was intrinsically the easiest of the four tests that resembled the training series, to be very much the hardest. The method transferred, where transference was a disadvantage.

In the tests essentially unlike the training series, the trained observers again showed superiority over the untrained control-group, which suggests that a transferable mnemonic system is not the only factor in improvement. The factors that influenced the essentially dissimilar tests, as Fracker points out, were: (I) the discovery that imagery is helpful. The special imagery developed in training may not itself be trans- 
ferable, but experience with it suggests the idea of deliberately employing some kind of imagery. In the training series, imagery had been unconsciously developed, and only recognized later. (2) "The factor of attention and its control seems to be an important one in improvement and transference," being ranked second to imagery, by the observers. (3) Association: but this factor does not come out very clearly in the experiments. (4) Automatisms. These may either help or hinder in transference. They make a method less adaptable, but where the method can be applied in toto, or at least without change in the automatised factors, they are a distinct advantage. The great improvement in the four grays in the final tests, and the small improvement in the four tones, illustrate both points. In the former test, every automatism could be transferred; in the latter, the use of numbers in the response had to be broken up.

II. Sensory and Sensory-motor Skill. By this rather inadequate title I wish to designate the great group of functions - using the word in Thorndike's sense-that have much to do in a rather superficial way with things, and very little to do with ideas, or interpretations of things. Such are Thorndike and Woodworth's experiments on estimating areas and weights, in perceiving words containing certain letters, etc.; Squire's experiments on neatness; and tests made by various psychologists on localization of lines, on discrimination of pitches in tones and shades in colors. Even Ruger's experiments with mechanical puzzles belong mainly in this group, for, while they involve mathematical principles, and might be solved by direct application of those principles, yet it is doubtful if anyone has ever applied that method, and Ruger's observers certainly did not. They simply manipulated the puzzles more or less blindly until they fell on the solutions by accident. Experience became somewhat of a guide, but only in a rule-of-thumb sort of way. I shall consider the data in this field under three heads: (I) motor skill, (2) sensory skill (discrimination, accurate perception, etc.), (3) generalthose activities which involve rather ingenuity than either fine motor co-ordination of especially accurate sense-perception.

I: Transference in motor skill. Of the numerous experiments in this field, most seem to have been concerned with transference of improvement in reaction times, where motor co-ordination is of the simplest sort. Most of the others have been of what I might call an "unreal " kind-such as learning to repeat the alphabet forward and backward, then inserting $\mathrm{n}$ after each letter ( $\mathrm{AnBnCn}, \mathrm{ZnYnXn}$ ) to test for transfer of improvement from those as training series to the test series 
$\mathrm{AxBxCx}$, etc. They lead on the whole to the conclusion that the transfer of training in such work is very limited. A test much more comparable to problems of real life was made by Scholkow and Judd, who tested boys of grades 5 to 6 in school, at hitting a target under water. I quote their report: "One group of boys was given a full theoretical explanation of refraction. The other group of boys was left to work out experience without theoretical training. These two groups began practice with the target under twelve inches of water. It is a very striking fact that in the first series of trials the boys who knew the theory of refraction and those who did not, gave about the same results. That is, theory seemed to be of no value in the first tests. All the boys had to learn how to use the dart, and theory proved to be no substitute for practice. At this point the conditions were changed. The twelve inches of water were reduced to four. The differences between the two groups of boys now came out very strikingly. The boys without theory were very much confused. The practice gained with twelve inches of water did not help them with four inches. Their errors were large and persistent. On the other hand, the boys who had the theory, fitted themselves to four inches very rapidly." ( $15, \mathrm{p} .37$.) There is one important difference in method, which no one has observed, between this and all the other transfer-tests yet published. Instead of taking the record of a single test with the water at four inches as the measure of relative improvement for the boys with and the boys without theory, the experimenters gave a fairly long training in the changed conditions, and measured the relative rates of improvement. The record for the first few trials at a depth of four inches is not given, but it would have shown a much smaller gain, at the best, for the boys with the theory, than the record showed as it was actually taken. If we compare the usual method of testing for transfer, with the "method of free reproduction" in association tests, then Judd's method in this experiment is analogous to the "saving method." Besides this point of method, there are two points especially important in the results: (I) without a certain minimum of experience, theory can afford no help; (2) given that minimum of experience, theory is transferable to all analogous situations, to great advantage.

Experience in every-day life bears out this conclusion. That athletic experience can and does transfer with a high degree of efficiency is a matter of common knowledge: experience in football often facilitates the learning of basket-ball; experience in baseball helps in tennis. This observation is not to be ruled out of court on the ground that the person 
whose experience seemed to transfer was only better in natural ability, for the one who began tennis, for example, without previous experience in other sports, sometimes proves his superior native ability by ultimately outstripping his opponent whose athletic training had given an initial advantage. The transference can be explained by the theory of identical elements. But I can speak with fuller knowledge in the field of music. Mastery of one instrument does make it easier to learn another, quite apart from the advantage gained by learning to read music and keep time. Mastery of two or three instruments gives a tremendous advantage in the early stages of learning a new one, though after this initial advantage, in which a saving of as much as two years' work may be made, then progress is no more rapid than for one of the same attainments who knows no other instrument. I shall cite one case which I had a chance to observe very carefully. An amateur violinist of good average ability, and given to theorizing on the principles underlying the rules of technique, took a few months' lessons on the piano. In laboratory tests his reaction times were found somewhat slow, and his accuracy in remembering movements of forearm and upper arm was not above the average. But his rate of learning on the piano was at first very rapid, scales were readily learned, independence of finger action, especially required in using both hands at once, was easy, and he acquired within two months considerable readiness at playing loud and soft simultaneously with different fingers of the same hand, and at playing simultaneously legato and staccato-in simple pieces, of course. The correct action for the staccato touch was learned in three lessons. Curiously enough, while the advantage of training had been with the left hand, that hand proved awkward and troublesome on the piano, while the right hand fell quickly into correct habits, and apparently was superior even in strength. This suggests that the direct muscular training acquired on the violin was the least factor in the transference, and that the gain was almost wholly due to a better understanding of the conditions of muscular training: particularly a greater power of sound self-criticism. The student had learned to recognize when an action "felt" right, and where to look for faults when it did not. It is further significant, that he showed least advantage from previous training, in the one place where understanding can least take the place of plodding work in muscular habituation: in learning to estimate accurately the distances on the keyboard for various musical intervals he had little advantage over an untrained student, and had gained but little fluency by the end of his period of study. 
2: Transference in sensory skill. It may seem an abuse of words to speak of sensory "skill," since we think of skill as essentially motor: but ability to discriminate shades in color, differences of pitch, intensity, and quality in tone, length and form in lines in figures, etc., certainly is at least analogous to what we call skill in the use of the limbs and muscles. The experimental data in this field are not very satisfactory. Two of the most often quoted studies are that reported by Thorndike and Woodworth in I9OI, and that reported by Coover and Angell in 1907. Since they come from what are generally regarded as opposing camps, we may reach something like reliable conclusions by checking them off against each other. Thorndike's experiments tested the gain in accuracy of judging the areas of various-shaped figures from Io to 100 sq. $\mathrm{cm}$. in size, of rectangles from $140-300 \mathrm{sq} . \mathrm{cm}$. in size, and of various-shaped figures from $140-400 \mathrm{sq} . \mathrm{cm}$. in size: after practising the observers on a training series in estimating the areas of rectangles from to to roo sq. $\mathrm{cm}$. in size. They also reported other experiments with lines and weights, resting on the same principle. The tests in ability to perceive words containing certain letters have to do with quite a different thing than sensory skill, and hence will not be discussed here. The results show an undoubted transfer of training, which the investigators explain as due to (I) acquisition of certain improvements in mental standards of areas; (2) learning to make allowance for constant error. "That there was no influence due to a mysterious transfer of practice, to an unanalyzable property of mental function, is evidenced by the total lack of improvement in the functions tested in the case of some individuals" $(27$, p. 276$)$. Here we see, what we have already noticed in other fields, that the chief gain is rather in an improved power of the understanding to find short-cuts in dealing with material, than in an increased efficiency of the sense or senses themselves. Our instruments do not improve: we only learn to use them better. Those who do not learn to use their instruments-the muscles and senses-from practice, show little or no transfer of improvement from the practice. Thorndike and Woodworth explicitly recognize this. They remark: "With some subjects in some cases the new ideas or the refinement of old ideas produced by the training seem impotent to influence judgments with slightly different data." (27, p. 395.)

Coover and Angell tested the improvement in discriminating shades of gray, after a course of training in discrimination of intensities of sound. The fact that the control-group actually got worse between the preliminary and the final results, makes one rather uneasy about the reliability of the 
results: we should like a little firmer assurance that such is the normal effect in this kind of work, before accepting these results as final. But even allowing for this weak spot in the tests, it is generally admitted that they prove the existence of some transfer: the only dispute is as to how much they show. In explaining the results, the authors say: Improvement seems to consist of divesting the essential process of the unessential factors, freeing judgments from illusions, to which the unnecessary and often fantastic imagery gives rise, and of obtaining a uniform state of attention which is less than the maximum. . . The factors in this transfer are due in great part to habituation and to a more economic adaptation of attention, i.e., are general rather than special in character." (4, pp. 333-4.) Instead of speaking of the factors as "general rather than special in character," it is less ambiguous to say that they are central rather than peripheral; that the improvement is due to a better understanding of and use of the psychophysical organism-or that part of it involved in the process studied-rather than to a change in the constitution of the organism. Thorndike and Angell are at one on this point, though I believe they do not recognize the fact. Both deny the spread of training-to any great extent, at least-through a change in the physical factors (the muscles and senses), and both stress the importance of the mental factors. Their differences are in the view they take of some of the higher mental functions. For Angell, attention is one function; for Thorndike, it is many: in the one case, it can be thought of as functioning more generally than in the other. Concerning the question involved in this dispute, I shall have more to say later: for the present, the important thing to notice is their agreement that the chief factors in the transfer of improvement found in their experiments, are mental. The senses involved have not become appreciably finer, subtler, in their responses to stimuli, but the mind has learned better how to put them to work, and how to read their reports.

3: General. Transference in problem-solving. Under this heading I shall take Squire's and Ruediger's experiments on neatness, and Ruger's experiments with mechanical puzzles, as typical. Squire found in tests of children in the intermediate grades that efforts to teach the children neatness in the arithmetic papers brought about a marked improvement in those papers, but an actual decrease in both neatness and accuracy in language and spelling papers. The explanation is obvious when we reflect that improvement involves two factori, the will to be neat, and the ability to accomplish neatness. Neatness is not a characteristic virtue of the elementary 
grades, and when the teachers would pester the children about their arithmetic papers, the children naturally made up for it by slighting their other work, so long as nothing was said about that. The experiment should have been carried further. By dropping the emphasis on neatness in arithmetic, and turning the attention to the spelling papers, the investigators would almost certainly have found a marked falling off in neatness of the arithmetic papers-though not a complete return to the old standard-and would have found improvement more rapid in the new subject than in the former one. Given the will to be neat, the skill acquired in the work on arithmetic papers can perfectly well be transferred to work on other papers: but the amount of automatic, involuntary transfer from one activity to another is certain to be small. Ruediger partially recognized this fact, and made a series of tests on neatness, in which, besides working actively for neatness in one subject, the teachers continually brought the ideal of neatness before the children, though making no special allusion to the other school subjects. The result was an unquestionable improvement on the average in all subjects, though the improvement was greatest in the subject where it was emphasized. But while these tests found a half-unconscious transfer of the will to be neat, they do not attempt to discover how far skill in neatness can be transferred by conscious, deliberate effort.

Ruger's report on his tests with mechanical puzzles is full of instructive material on the learning process, but only his data and comments on transfer will be noted here. He reports three tests on the transfer of specific motor habits:

(I) "A subject was tested with a puzzle thrown in chance positions, then trained to approximately the physiological limit in handling four special but important positions. He developed no general rule to include his treatment of these special positions. Another subject was trained entirely with chance positions, in a series approximately half the length of the first subject's series. The second tests of the first subject showed no improvement over the initial results, and were inferior to those of the second subject. This failure to profit by the highly specialized training seems to have been due to the lack of a generalized rule of procedure. As it was, each chance position was first reduced to one of the four special positions and then the solution was proceeded with instead of being performed directly." (23, p. I8.)

(2) "A certain puzzle was so arranged that it could be presented in various forms. The manipulations for these various forms could all be comprised under a single formula. 
This general formula could be deduced from any one of these special forms. A number of subjects were tried with this puzzle. As soon as skill was acquired in dealing with one form of the puzzle it was changed to another form. The subjects who developed the general formula during the solution of the first form were able to use the specialized habits built up in the first form in the second. Those who formed merely the special habits without developing the principle attempted to carry over the habits without modification and were greatly embarrassed by the change.

(3) "A subject was tested with a puzzle in a given form. Then all the motor habits necessary for the rapid solution of this form were built up by practice in the separate acts of manipulation involved. The elements were organically related in the successive forms of the practice series, so that the practice was not on the separate elements merely but on their connections. At the close of the practice series the subject was given the complete form, which was identical with that of the initial test. This form was not recognized as being related to the practice series, and the habits built up there were not brought into use.

"In general, the value of specific habits under a change of conditions depended directly on the presence of a general idea which would serve for their control."

This is fully in harmony, we see, with the principle already stated, that most, if not all, transfer is central, not peripheral. An idea or an ideal can be readily adapted, adjusted to the new conditions: a motor, sensory, or sensory-motor habit, if highly developed, must be taken over unchanged, or changed at the cost of much effort; while if it is not highly developed, little is gained by its transference. A new habit could almost as easily be built up.

The report just quoted raises the question: why do motor habits sometimes transfer when they should not, and not transfer when they should? The answer is fairly obvious in this particular case: the transfer resulted from a mistaken assumption of similarity in the two cases (see above, Ruger experiment 2); the failure to transfer (Ruger, 3) from nonobservance of similarity. When we turn to every-day experiences, however, the problem seems more intricate, for we find cases of transfer occurring even against the will of the agent, and non-transference where the agent is actively trying to bring the habits into play which refuse to transfer. The solution of the problem is, I think, substantially the same as before, except that in place of conscious perception of simi- 
larity, we have a more or less unconscious reaction to similarity, which calls up the seemingly most appropriate "set," and with it, the habits which long-continued practice has associated with it: the undesired habits thus called in crowd out the other habits whose transfer is desired. Apparently we can only approach just so close to the groove of an established habit without slipping in, willy-nilly.

We conclude, then, that "improvement of functions" by training is wholly, or almost wholly, central, not peripheral -not a new doctrine, certainly, but one whose consequences have been often overlooked even by those who hold it. $\mathrm{Me}$ morial work does not train the memory either as a whole or in part: it merely stamps in certain impressions. Motor work does not train a "motor function"; it only forms certain motor habits, or tendencies to repeat the specific acts that were performed in that work. These habits do not transfer even to the most similar situations unless the similarity is taken for identity; and in that case they transfer unchanged: nor do they have any immediate effect in making other habits easier to form. But in doing motor work, or memory work, we can also observe how it was done, and use the "know how" thus acquired to make our next bit of work more efficient. Experience can teach us how the memory behaves, just as it teaches a mechanic the behavior of his materialwood, iron, tin, or stone-and this understanding of the behavior of memory, muscle, the senses, and thought, constitutes the real and only direct training possible in any of these fields of work. In its applicability, this training is universal, for memory behaves in substantially the same way whether dealing with nonsense-syllables or philosophical prose: the laws of muscle-action are essentially the same whether the work be driving nails or setting a bone. Very few of us are penetrating enough in our analysis of these laws, or judicious enough in their application, to secure this universal transfer: we only accomplish a very limited transfer, because the strangeness of the subject-matter, when we get too remote from the material with which we had our original experience, baffles our attempt to discover the community of underlying principles between the two. It is easier to work up our experience clear from the beginning, again. But the possibility of universal transfer is always with us: how extensive a transfer any one can achieve from a given bit of experience depends on the amount of intelligence which he devotes to the task. 
In accomplishing this transfer of training, if one can use habits already formed, as components in the forming of new habits, he saves just so much in the process: thus we have an indirect transfer-value of existing habits. Where one has a countless number of habits already formed, as in the use of the hand and arm, or a countless number of memorial impressions established, as we all have in our mass of knowledge, this transfer-value is of tremendous importance for the formation of a new habit, or the establishment of a new memorial impression: where the transfer is only from one small habit or memory to another, the transfer-value is relatively insignificant. But in any case, the use of intelligence is necessary to realize the transfer-value: habits can rarely be taken over bodily and unchanged. They must be adapted, and in adapting them, one must be able to distinguish essential from apparent similarity and difference in the two situations. A wrong diagnosis results in misadaptation to the new case: habits and parts of habits transfer that should not, and those that should transfer fail to do so.

All but one of the tests for transfer that have come to my notice, have made one serious error in method: that one is the experiment by Judd and Scholkow, mentioned above (p. 357). In actual life, the thing of value is not the gain in efficiency found at the very beginning of a new activity, due to training in something else; but the gain in improvability. Not how much unconscious, automatic transfer has already been effected, is the question of importance, but how much transfer can one effect by the use of intelligence and deliberate effort, given time to adjust himself to the new situation, to seize its points of essential similarity to the old situation, and of essential difference. Therefore, instead of taking the record for immediate improvement in the final test series, as the measure of transfer, experimenters should after the training series, make of the final tests a new training series, and compare the rate of improvement for the trained group and the control group in the final test-training. In experiments involving such things as simple reaction-times, we should expect very little difference, for they give little scope for the use of intelligence: in tests of greater complexity, such as, say, transfer from typewriting to telegraphy, we should expect a marked difference. The more intelligent should at first greatly outstrip the control group, then settle down to a normal rate of improvement, keeping their advantage, but making no further gain over the control group. The less intelligent should in some cases lag behind the control group, from transferring the wrong habits, which would interfere with progress. 


\section{Learning and Transfer in General.}

The results found in these experiments are of only symbolic value for education: they do not test the activities that mean most for life, but only very small analogues and elements of the activities and abilities that are supposed to distinguish a leader from a follower, a cultivated man from an uncultivated, a master from a tyro. The bigger question now confronts us: what is education: can one acquire improved power for meeting novel situations, as well as greater familiarity with old ones; can college training fit for business, and if so, how; have different subjects their peculiar cultural value, and if so, in what does it consist? The remainder of my study will be devoted to the principles on which rest the answer to these questions.

Nearly, if not quite, every fact and principle that has any bearing on the question of formal discipline has already been noticed by writers on the psychology of learning. The "one thing needful" is that these facts and principles should be brought together, their relations to each other made clear where they have been overlooked, and the whole reduced to coherence. In attempting this task, I shall follow very largely Thorndike's Psychology of Learning, probably the soundest and certainly the completest work that we have on the subject. For clearness and convenience of reference, I shall preface my discussion with a brief abstract of his account of the mechanism of learning. He distinguishes the following laws of learning:

I. Three main laws of learning.

(a) The law of readiness: When any conduction unit is in readiness to conduct, for it to do so is satisfying; not to do so is annoying. When it is not in readiness to conduct, for it to do so is annoying.

(b) The law of exercise:

(I) The law of use: "When a modifiable connection is made between a situation and a response, that connection's strength is, other things being equal, increased." (26, p. 3.)

(2) The law of disuse: When a modifiable connection is not made between a situation and a response during a length of time, that connection's strength is decreased." (26, p. 4.)

(c) The law of effect: "When a modifiable connection is between a situation and a response is made and is accompanied or followed by a satisfying state of affairs, 
that connection's strength is increased: when made and accompanied or followed by an annoying state of affairs, its strength is decreased." (26, p. 4.)

II. Five secondary characteristics of learning.

(a) Multiple response to the same external situation. This is the universal method of meeting a new situation: we try various new responses until we find one that satisfies. In animal learning, the responses are almost purely blind, random movements; in man they may be guided, stimulated, or checked in various ways, but the principle remains the same. It is only though this principle that we can break away from our plexus of habits, meet new situations, and form new habits.

(b) Attitudes or "sets." These determine the general character of the multiple responses aroused by the new situation, and what response will be selected out of those appearing. The relation between the set in a given situation, and the laws of readiness and effect, is very intimate. One's set determines what conduction units shall be in readiness to conduct; and this determines what responses will satisfy or annoy.

(c) The partial or piecemeal activity of a situation. One or other part of a situation may be prepotent in effect: in more popular language, we tend to analyze situations, and respond to those parts only that seem important, or convenient to take first.

(d) Assimilation of response by analogy. "To any new situation man responds as he would to some situation like it, or like some element of it." (26, p. 28.) "Were the situation so utterly new as to be in no respect like anything responded to before, and also so foreign to man's equipment as neither to arouse an original tendency to respond nor to be like anything that could do so, response by analogy would fail. For all response would fail. Man's nature would be forever blind and deaf to the situation in question." (26, p. 29.) To what experience any situation shall appear similar, depends on the man and his previous education. Coal dust has a similarity to diamonds in the mind of a chemist: to an uneducated man it would be similar to something of a quite different sort.

(e) Associative shifting. This depends on the same principle as response by analogy. We readily learn to make the same response to part of a situation that we have done to the whole: and we may come to lose sight of 
the whole in our response to the part. The very existence of language is a result of this principle; the danger against which we have always to guard of mistaking the word for the thing, is the result of a tendency to make the associative shifting too complete.

This analysis of the mechanism of learning may be left without comment, since the points on which it might be challenged are not relevant to the present study: but certain other points in Thorndike's treatment of the psychology of learning, which have a bearing on the question of formal discipline, need to be criticized and supplemented. These are his discussions of (I) habit, (2) thinking, (3) functions, (4) attention. On all four of these subjects Thorndike is vague-purposely, as I take it, from unwillingness to introduce any speculative question or anything of doubtful validity into his book-and consequently I write here in constant danger of misinterpreting and misrepresenting him. But psychological thought has progressed far enough to make possible something like a definite determination of what these four terms should mean.

(I) Habit. "To one accustomed to the older restricted view of habits, as a set of hard and fast bonds each between one of a number of events happening to a man and some response peculiar to that event, it may seem especially perverse to treat the connections formed with new experiences under the same principle as is used to explain those very often repeated, very sure, and very invariable bonds, which alone he prefers to call habits." (26, p. 28.) Not exactly perverse, we might reply, but rather confusing. The difficulty seems to lie in this: Thorndike calls the laws of learning which have just been given, "laws of habit," and then apparently assumes that every process which obeys those laws is a habit. But they are laws of habit only in the sense that they are the mechanism by which habits are formed: every process which obeys those laws has in it the makings of a habit, but has not yet become one. Once let the process became a habit, and several of these laws fall into abeyance. Multiple response, for example, is supplemented by the uniform, unvarying, and even undiscriminating response of the fixed habit; associative shifting can only be accomplished at the expense of the habit; and the principle of assimilation is only a source of embarrassment, unless one is able to adapt-that is, partially break up, and re-formthe habit thus transferred. What, then, is a habit? A habit is a tendency to repeat an action which has often been performed before. So far as the action has become habitual, 
it will be repeated unchanged. Habits and memory are essentially one, arising from the universal tendency of the neurones to retain impressions. Habit and memory are static: a habit cannot form itself, nor can it form another habit. The power that forms it must come from outside itself. That power is the whole personality, feelings, impulses, thought: most active of these is thought.

(2) Thought. As habit is a fixed mode of response to an old situation, so thinking is a flexible, tentative response to a new situation, having as its purpose the discovery and selection of the best response. Having found this response, the organism generally turns it into a habit, and leaves thought free to attack another problem. Thought is, in terms of Thorndike's analysis of learning, the action of the principle of multiple response, under the guidance of a 'set:' it is constantly trying to put things together in a new way, looking for new relations, and in this effort, makes use of its previous acquisitions, habits, memories, established associations, as material. No doubt thinking is much more than this, but it is at least this, and we must carefully distinguish between thought, which is active, tentative, flexible, directed toward the new, and habit, which is unprogressive, stereotyped, a mere deposit of the past-though none the less important for that. Thought may abdicate to habit, and in great measure does in most adults-perhaps completely in some-but thought is not habit, though it is such stuff as habits are made of. There are no habits of thought, strictly speaking: what are so-called are habits that condition thought by barring its progress in some directions, and consequently directing it another way; and also habits which constitute the material with which thought works.

(3) Functions. "Let us use the term 'Mental Function' for any group of connections, or for any feature of any group of connections, or indeed for any segment or feature of behavior, which any competent student has chosen or may in the future choose to study, as a part of the total which we call a man's intellect, character, skill, and temperament. By so catholic a definition we shall have a convenient term to mean any learnable thing in man, the psychology of whose learning anybody has investigated." (26, p. 57.) Such a pragmatic use of the term is of course perfectly legitimate, but we shall want to know more definitely whether a function as such has an organic unity, a nucleus in some innate character and a capacity for independent growth, or whether it is a mere 'segment of behavior' chosen more or less arbitrarily, for convenience of study. In the former case we 
have a great group of little faculties in the mind: in the latter case the mind would be from one point of view an aggregate of atoms; from another point of view, a unit. If functions are faculties, we should expect much transfer in a small field, but no transfer to other functions: if they are not, then possibility of transfer should be as wide as the mind itself, and the immediate spread of training should be practically nil. Thorndike seems to lean to the latter view, but occasional remarks by him and others of his school suggest a tendency to regard functions as faculties. For example, Ruger asks: "Is there a single function for "transformations in three dimensions,' or are there numerous special functions?" $(23$, p. 26.) Thorndike and Woodworth say $(27$, p. 248) "the function attention, for instance, is really a vast group of functions": from which but one inference is possible, that there are as many "attentions" as there are other functions, and that each "attention" is attached exclusively to one of these functions, since no function can act without attention. This leaves us in doubt as to Thorndike's position. But considered on its merits, the second view proposed, denying to "functions" any independent, innate origin, seems the preferable. On this hypothesis, a function is to be regarded as a group of habits and a body of knowledge which have a certain unity from serving the accomplishment of one general purpose. It centers, not round an internal, psychic nucleus of some small special ability, but round the external nucleus of an end to be attained. It may, however, acquire a unity and an independent existence much resembling that once attributed to a "faculty," through becoming formed into a constellation or complex. Thus "mathematical ability," if the study is pursued for a long time and without care to relate it to the rest of life, may be organized into a separate complex, dissociated from everything else-it becomes a "water-tight compartment."

One important conclusion partly follows from, partly supports, this hypothesis. It is this: within the field of pure intellect, there are no special abilities. So far as power of thought is concerned, any individual is equally well equipped for mathematics, philosophy, or fiction-writing: the Anlagen which determine anyone's special abilities and interests are all extra-intellectual-emotional characteristics, memory-type, motor control, and environment are among the most powerful determining factors. This conclusion rests mainly on physiological and genetic grounds. Physiologically, uniformity of intellectual power within the individual is to be assumed for the same reason that we assumed uniformity of memorial 
ability. As memory has for its basis the power of the neurones to resist impressions, so thought has for its basis the conductivity of the nerve-fibers in the brain. The better one's nerve-fibers conduct, the more fertile will his mind be in new combinations-or ideas-and the more often will he be able to hit on a good idea. There is no reason to suppose that this conductivity varies in different parts of the brain, while the fact that in thought we can summon what little we do know in uncongenial fields, and use it as readily on occasion as we can use knowledge from our favorite fields, indicates that the brain is an equally efficient conductor in all its parts. Genetically, it is not easy to see how specializations in the field of thought should occur. We can easily understand sight-centers, auditory centers, speech-centers, hand-and-arm centers; but how explain mathematics-centers and philosophy-centers: or, taking smaller " functions," centers for puzzle-solving, and centers for judging rectangles of approximately a given area? The facts of learning are much more easily explained without supposing such " centers." This explains in a new way the correlations which Hart and Spearman have pointed out, and for which they have postulated a "general factor." Granted that different parts of the brain are equally efficient in the quality on which intelligence depends, they will be correlations without the help of an ubiquitous "general factor."

(4) Is attention one function, or a group of functions If our contention concerning other functions is granted, then attention must be one function, for it is the prerequisite of every activity, and if it does not attach, in separate fragments, to separate innate faculty-like functions, it must attach instead to mental activity in general: that is, it must function as one. Two other considerations support this view, even if we supposed the innate origin which we have just denied, of separate "mental functions." (a) Attention can be concentrated. If there were a great variety of separate "attentions," the amount of attention available for any one function would be strictly limited, and show very little variation. (b) Supposing attention not to be one, the " attentions" belonging to two unrelated functions could work simultaneously without interference in consciousness: the more remote from each other the two functions were, the less would they interfere. Instead of that, we find that we can attend at one instant only to so much material and of such a sort that it can be contemplated as a unit: the more unrelated an idea that tries to crowd in, the more distracting its influence. 


\section{The Things That Transfer}

I. Knowledge and Ideas. The distinction in meaning between "knowledge" and "ideas" may be caught by comparing the phrases "a learned man" and "a man of ideas." Taking the suggestion from these phrases, we may define knowledge as what one learns from others; and ideas as what he works out for himself. By this definition, what were ideas to Plato or Kant, become merely knowledge to me, unless I reconvert them into ideas by working them out for myself. The distinction is vital, for what we retain as knowledge is never more than what appears on the surface-we can reproduce it all-while what we possess as ideas have behind them the richness of the thought which went into them-the least part of an idea appears on the surface. Consequently, while a bit of knowledge and an idea may look exactly alike, they are vastly different. To Kant, the Critique of Pure Reason represented the fruit of years of thought: a sentence of it might stand for whole volumes. To us, if we only read it to find out what he said, it will be little more than, in Hamlet's phrase, "words, words, words." We can only win from it something of the significance it had for Kant, by getting into sympathy with his point of view, putting ourselves into his place, trying to understand why he held this or that position, and thinking his thoughts over after him. This is the creative reading which Emerson urges upon us. It by no means involves even temporary assent to the doctrines of the author whom we happen to be reading, but it does involve recognizing that he was human 'of like thoughts with ourselves,' and reading his work sympathetically, as the honest effort of a human mind to express the thoughts that came to it.

Both knowledge and ideas are capable of transfer: but knowledge can never transfer of itself. It must first be worked up into ideas-that is, adapted, re-formed and reorganized, for the purpose at hand. We see this impotence of mere knowledge, everywhere: we all know boys whose knowledge of physics coexists with methods in their everyday mechanics that go back to the cave-men; girls to whom chemistry and cooking have no relation. I know one excellent teacher of geometry who on attempting a little amateur carpentry never thought of using the principle of the right triangle to get the length of his rafters and the proper bevel of their ends; but set two timbers up on the sills at what seemed an acceptable pitch, got someone to help hold them, and marked with a pencil where they crossed. A little 
thought might have suggested from his knowledge of geometry the principle which trained mechanics, though themselves ignorant of geometry, have been taught to use: but human nature seems prone to make the hands save the head, instead of making the head save the hands. Anything to get out of thinking.

This points to the true nature of the gap between theory and practice, and how it is to be bridged. Theory is a statement of the relations between one bit of experience and another: and as soon as it loses touch with the experience out of which it grew, it becomes meaningless. The "mere theorist" is not even a theorist: he is only a depository of theories worked out by others, which to him are merely knowledge. But he has this advantage over the "practical man" who knows no theory: let him once wake up to the fact that his knowledge has meaning when brought into contact with life, and he has the store of knowledge already to be worked over into ideas-into power. This is a partial justification of the school, for giving so much of its time to teach theories which can find little or no contact with the pupil's present experience. The pupil is not necessarily the worse off for possessing knowledge which does not relate to his present experience: while he is far better equipped for the future time when his knowledge will become significant, and if he is alert, the very possession of knowledge which he cannot relate up to life, will of itself challenge and enrich the assimilation of his school-learning to experience. But this consideration in no way justifies the school in accentuating the break between theory and life. We may frankly recognize that much of the subject-matter of our school studies-even history and geography-will not reach its highest significance to the pupil until years afterward, and that we need not worry over the fact: but we must make so much of it as we can relate to his life, or, if he is an average boy, the idea will never dawn on him that schoollearning can be applied to every-day problems. Learning remains to him a thing apart.

II. Attitudes and Ideals. The Aufgabe and the Einstellung, the controlling factors in all thought, are for that very reason, controlling factors in all transfer. In studies of learning, it is usual to bracket the two as parts of one process, and then focus attention mainly on the Einstellungquite naturally, because only through the Einstellung does the Aufgabe get results. But in a study of transfer, the distinction between the Aufgabe or goal-idea, and the Einstellung or "set," must be kept clear. 
(a) The "set." The set is the bondservant of the goalidea, the adjustment which the organism makes in obedience to that idea. Any such adjustment is to be counted efficient only in proportion as it gets the results called for by the goal-idea. But any given "set," if often enough assumed, can become habitual, and so lose its intimate dependence on the goal-idea. Then we have something that looks very much like a formal habit. As in the humbler realm of activity, conscious, deliberate reaction to a new stimulus turns into habitual, automatic reaction to the stimulus after it has been often repeated: so in the realm of purposes and adjustments to them, the purpose at first determines the adjustment, but at last, if we often meet the same situation with the same purpose, the adjustment becomes automatic, and may even conflict with the purpose, while it will certainly persist without the help of the purpose. A page from my own experience, which many another language-student in our country can match, will serve to illustrate. In college, I studied my texts in foreign languages primarily for the purpose of being ready for translation in class. As I gained some familiarity with the languages studied, I acquired the habit of reading merely to make sure that I could translate when called upon, only passages or words that required working out or looking up, attracted my attention. Passages that contained no difficulties were passed by with a sort of subconscious comment, "yes, I can do that;" and without thought of the subjectmatter. The result is that since my college days, now that $I$ read for subject-matter, I find it almost impossible to get any connected idea of the content of a book in a foreign language until the second reading, and often the easier the text, the less I get. I acquired in college what Thorndike calls a "habit of neglect"-learning to neglect the subjectmatter, because class-work made no call for it-and the habit has stubbornly persisted in spite of constant effort to break it up.

These crystallized sets, which have declared their independence of the parent goal-ideas, are the most important of the so-called "habits of thought." A set, whether become habitual or not, forms during the period of its dominance, the channel within which thought must flow: become habitual, it acts as a unvarying controller of thought in the presence of situations which call up the given set. A single set, or a small group of them, may after a period of long habituation, so dominate the mind that thought dares not and cannot leap their bounds. Thus the mathematician, the historian, the financier, the specialist in any line, may so firmly acquire 
a set appropriate to his own line, and be so innocent of any other forms of thought, that he transfers this one lone set of his to everything that he does. More precisely, this habitual set often makes the man unable to see facts and values that lie outside the sphere of his particular work. There are lawyers in whose minds the statute law usurps the place of the moral code: and another case in point is the business man who thought that he had struck a death-blow to literary culture by arguing that knowledge of Shakespeare had never helped anyone to win a speculation on the stock exchange.

The set transfers more readily than other kinds of habit, because it is attached rather to the general outline of a situation than to its full concrete reality: thus a far wider variety of situations occur that are, so far as concerns the elements evoking the given set, identical. For example, one who acquires the habit of contradicting people, needs only to encounter a statement of fact or opinion in conversation, and his habitual set is at once called up. The statements to which he reacts at various times may be as unlike as day and night, yet they are identical in form, both being assertions. Let the medium of conversation be questions, concealing the speaker's opinions, and the habitual set of the contentious person is helpless to act. The reaction was to the form of the remarks, and changing the form, we evade the reaction.

(b) The goal-idea. From its very nature, the goal-idea cannot become habitual. It is essentially an act of will, and though we may habitually do a thing, we cannot habitually will a thing. Just so far as habit enters in, volition drops out: it is no longer needed. So when a set becomes habitual, the goal-idea to which it belonged fades out, and is very often lost sight of. This is a valuable labor-saving device, because it saves us from the necessity of thinking out our purposes anew whenever we meet a situation: but it is also dangerous, if not carefully used. In any occupation which involves much routine-and most do-one is in great danger of making a fetish of things which were originally done for a purpose, but have become so fixed from constant repetition that they are at last done automatically, worshipped as ends in themselves, and may even serve to defeat the purpose which they should have served, but which, now lost sight of, can gain no respect. School discipline, hospital rules, legal procedure, contain endless illustrations of this irrational worship of form due to divorcing the set from the goal-idea.

Sets may be taught; goal-ideas can only be evoked, brought 
to consciousness. What one wants is an expression of what he is; but one may not be at all clear as to his own nature, nor as to his own wishes. The great business of education is to help him find himself, to help him to understand what he is, and what are the best means of realizing fully the possibilities of his own nature. One may very easily choose the wrong intermediate goal-ideas, and so defeat the end which he wishes to serve. Education, in preparing him against this, does in a very important sense teach him goal-ideas, but only, as said before, in the sense that it evokes them from his own nature. But school education very largely fails in practice to do this, because it has very little thought of the individual, and still less of such intangible things as purposes and ideals. Routine and facts are its mainstay. It can and does, however, through the knowledge which it gives, furnish a broader basis from which those who have come under its influence can work out for themselves more surely what their aims are and should be; and we must recognize that too much guidance here is as bad as too little. Every one must "work out his own salvation," or he will be the weaker for not having done so.

Ideals are the chief priests in the hierarchy of goal-ideas. What his supreme ideals are no one can say, for they have their roots too deep in the nature of his being. One who could define his ideals could give a complete analysis of his own nature and character: and the unfailing curiosity of everyone about his own powers and his own traits of character, his interest in what others have to say about him, is an index of the uncertainty with which he gauges himself. But if we can never attain a final statement of our ideals, and may even in trying to do so state the very opposite of the truth, yet we can sense them dimly, and feel them with enough certainty to work toward them. Education of the right sort can enable us to become more clearly aware of these ideals which we dimly sense: education of the wrong sort can blind us to them completely. But in any case, everything that we do is at bottom directed toward the realization of these ideals; or was in the beginnings, before it became, as a habit, independent of all aims and ideals, because independent even of the will.

Goal-ideas and sets alike can transfer, but the involuntary transfer of a habitual set is always in response to a formal, superficial identity between situations, which may coexist with a very essential difference in other respects, which makes the transfer mischievous. The transfer of a goal-idea is necessarily voluntary, through discovery of analogies between 
situations. It may be often mistaken, but the more clearly one understands his own aims and ideals, the more perfectly adapted will his transferences be. If he learns to think clearly, and gains an understanding of his own purposes in life, he is equipped to meet any situation, not necessarily in the best possible way, but in a better way than he otherwise would; because he is able to bring his past experience, thought, and decisions, to bear on it.

III. Reasoning. Reasoning always involves-and is-dealing with some kind of subject-matter, and consequently requires familiarity with the nature of the subject-matter dealt with, and adaptation to it. The kind of reasoning that succeeds in mathematics, will fail in historical study. It also requires a considerable stock of knowledge in the given field, for reasoning is very much like the process of digestion-it cannot go on without something to digest. But beneath the difference in reasoning processes consequent on difference in subject-matter, and beneath the conditioning fact that we cannot reason without knowledge to base our reasoning on, there is an essential similarity between reasoning processes even in the most unrelated fields. Any extensive discussion of the nature of reasoning would be out of place here, but we must notice what is the effect of practice in reasoning, and when and how it may transfer. Practice may have its effect in three ways: (I) it develops the so-called " habits of thought"-habitual sets, and perhaps "habits of neglect of fatigue and discomfort" -and thus relieves the strain on the voluntary attention, setting it free to focus more directly, on the thinking process itself. (2) It may improve one's familiarity with his subject-matter. This is of the very first importance. As one can only learn by experience to recognize objects under the microscope from the pictures of them in Dooks, so it is only intimate acquaintance with whatever the mind has to consider, that enables it to grasp the significant points, and distinguish and ignore the insignificant. (3) Practice may bring one to an understanding of "how it is done." This is not a matter of habituation, but of grasping the idea that the procedure employed makes a difference in the results. A man of sufficient genius might learn, from a single act of reasoning, enough to build up a whole system of logic-but no one has ever done it, of course. We can, however, supplement what we learn from first-hand experience, with what others have learned: and our books on logic, our scientific induction, our mathematical deduction, enable us to profit by the experience worked out by scores of great men, living generations apart. Practice, then, is supplemented 
by what we inherit from the experience of others, to an extent which we wholly fail to realize, in giving us an understanding of method in thought. But it must be clearly recognized that books and instruction can only supplement and guide experience. We learn from them of devices which would not have occurred to us, and we learn to look where without guidance we might not have thought of looking, for significant principles in our own procedure: but a device which we cannot use, a principle which we do not recognize in our own experience, is meaningless to us. We do not learn to reason by studying logic, though it may help us to understand some facts about our reasoning.

Now the question is: How far can practice in reasoning transfer? Taking in order the three main effects of practice just noticed: (2) The " habits of thought" may transfer involuntarily, wherever situations occur that are formally enough like those on which they were formed, to call them into action; or they may be voluntarily transferred and adapted, because found useful. Thus one who has trained himself to think in mathematics, in philosophy, and in biology, deliberately transferring his acquired habits, has in consequence developed habits flexible enough - or rather, perhaps, generic enoughto apply with a great saving of effort to any new field. But if the thinking in all three lines is conducted with no thought of relating the processes, we have "water-tight compartments" again. If, taking the third alternative, one tries to transfer his habits unchanged, he fails in yet another way. Pascal puts very clearly how this works in his own favorite subject: "Geometers never see what is before their eyes. They are brought up among the principles of science, clear and tangible every one; and all the arguments they employ have been carefully tested beforehand. Hence they are puzzled when they have to deal with evidence of a different kind. Here the points are almost imperceptible; they are not so much seen as felt; a man will hardly be got to notice them at all, if he does not do so naturally. They are so numerous and delicate that the very nicest judgment is needed to seize them and draw the right conclusions: for they cannot be set down in order, like the propositions of mathematics. The mind must take them in at a glance, rather than by any conscious process; geometers only make themselves ridiculous when they insist on applying their axioms and definitions to matters incapable of such handling. Not but what the mind does reason about them after a silent, instinctive fashion of its own, beyond the power of most to grasp, and of any to explain."

(2) Familiarity with subject-matter is of course useful only 
so far as the subject-matter itself enters into the work of other fields. But we very readily overlook even the extent to which the subject-matter applies: the self-same fact looks very different in school from the way it looks in a business office; and very different at church on Sunday than at work on Monday-and we do not recognize its identity when it puts on a different dress. Consequently we lose valuable transfer-possibilities, learning useful facts only to forget them again, because we did not learn them well enough to recognize them in a different setting.

(3) Far the greater part of transfer-possibilities in reasoning, come under the heading of experience in methods. Even transfer of habits, and of the use of subject-matter, must be presided over by this understanding of the basic principles of thought, to get the best results. By this understanding of the basic principles of thought, I do not mean the kind of conscious evaluation that could be worked up into a book on logic; but rather the instinctive grasp-analogous in a way to vigor of conscience in morals-on which the conscious evaluation of principles must rest, and which can exist without that conscious evaluation. No course of study can infallibly evoke this instinctive grasp: any subject may do it, if the subject appeals sufficiently to the student. Dewey had this partly in mind when he said: "Any subject . . . is intellectual, if intellectual at all, not in its fixed inner structure, but in its function-in its power to start and direct significant inquiry and reflection." ( 7, p. 39.) At the same time, some subjects are far more effective than others in this respect, owing to their fixed inner structure, if they can be made to appeal: because they can afford the student a far wider variety of "significant inquiry and reflection" in a more concentrated form.

IV. Moral Judgments. The teaching of morals is the most baffling of all problems in education, and the few remarks that can be made here can scarcely hope to add much toward its solution: but since transfer in and into the realm of morals is one of the most important things that the doctrine of formal discipline has to deal with, we must face the problem, were it only to confess defeat. In dealing with moral education, one principle may be laid down as fundamental. If, and so far as, we can influence morals through intellectual training, that is, for the school, at least, the best mode of attack. This is true for several reasons. In the first place, it relieves the serious difficulty met in finding teachers who can give direct moral training. A teacher who inculcates, by command of the school board, moral principles which find but 
a small place in his own life, can scarcely avoid making the instruction seem a mockery to his pupils: yet in selecting teachers, it would only put a premium on hypocrisy and timeserving, to go into their moral qualifications more minutely than we now do, in demanding that they measure up to certain broad, easily ascertainable standards. The roots of character lie too deep to be reached by any objective tests: and it is so easy to "assume a virtue if you have it not," with sufficient verisimilitude to deceive the average man, that we could scarcely expect moral tests to improve the personnel of the teaching profession, especially since every vigorous character would resent them, and leave the profession by the shortest route, rather than submit. In the second place, there is always danger that direct moral teaching will become either so aridly intellectual that it will have no meaning in terms of action, in the children's minds, and may even rub the bloom of their youthful enthusiasms; or else so sentimental and goodygoody as to repel the sturdier characters, and confirm the others in their priggish tendencies. Again, direct moral teaching must have to do very largely with particular acts. People demand tangible results, and this is the easiest way to get them: and besides, only a rare teacher could deal with anything like moral principles, without talking over the pupils' heads. The result, then, of the usual moral training must be to develop a purely formal morality, consisting merely of particular habits of behavior. An extreme picture of what such moral training can do in an earnest, conscientious man, is seen in Victor Hugo's character portrait of Javert.

If we can reach morals through the intellect, giving a firm basis for a sound morality, but leaving each one to work out his own character, we avoid all these difficulties. Everyone wants and needs, of course, the help of others in forming his character, but he naturally seeks this help personally and privately, not through the medium of class work. Can we find this desired intellectual basis, to be taught in school, for the formation of character? In several ways, I think. First, through the "intellectual conscience." This roots less deeply in sentiment than does the moral conscience, and so is less liable to perversion, and easier to reach. Intellectual honesty, for example, is simply freedom from self-deception. Generally speaking, no one is eager to deceive himself, so the teacher has little trouble in enlisting the will. He needs only to prepare his pupils against the errors into which thought readily falls, and so far as they learn to think soundly, they will be intellectually honest. But one who is honest with himself is far more likely to be honest with other people, 
because he has acquired the technique of honesty-and a great part of the dishonesty in the world is due to sheer inability to tell the truth-and because honesty seems to him more a thing to be desired, than to one in whose mind the distinction between truth and falsehood is less clear.

A second way of reaching morals through intellect has already been foreshadowed, in the section on ideals and goalideas. The laws of morality are only means to an end: the realization of ideals. One who has learned to orient his intellectual aims by his ideals is the readier to guide his conduct in the same way. Let him link up his moral principles with the rest of his life, and they will gain both in dignity and compelling power. Duty gets a richer meaning; conscience is recognized as a friend to be cherished. This approach, then, through intellect to morals, depends on bringing ideals to conscious recognition, and developing the judgment, as a power of selecting the right means to realize ideals.

A third means of moral influence, less distinctly intellectual, but a purer case of transfer, is through pre-forming moral judgments. We see ourselves as other see us, much more clearly, if we have first contemplated and judged the given act in someone else-even in a character of fiction. The parable of the ewe lamb, which the prophet Nathan used to bring David's crime home to him, is an illustration of this. If, then, through stories, children in school have a chance to judge coolly and without personal bias certain modes of behavior, those pre-formed judgments are there as a basis from which to judge their own behavior. The extent of the transfer depends on how fully they realize the identity between their own acts and the others on which they have passed judgment.

But one caution must be added: if we substitute the approach to morals through the intellect, for the direct approach, no one must infer that all reference to morals should be banished from the schools. It should not be made a subject of formal instruction, because morality at its best possesses a spontaneity and naiveté which formal instruction tends to spoil: but on the other hand, to avoid all reference to it as taboo would be just as bad as the other extreme of lugging it in by force wherever possible. Morality is as natural to humanity as is breathing, and one should feel as little constraint in speaking of the one as of the other. Any departure from spontaneity, in either direction, will throw an atmosphere of unreality around the whole subject, in the minds of most children. 


\section{The Mechanism of Transfer}

The reader may have noticed that throughout the whole of our study thus far, we have emphasized the fact that under certain conditions, knowledge and training may transfer: it remains to inquire what principles determine whether or not this transfer will come about. These determining factors are two, the one functioning as the medium, the other as the motive power.

I: The Law of Analogy. It is a commonplace to say that one cannot expect to meet any two situations that are exactly alike; yet we are constantly treating situations as identical with other situations which we have already met, and we treat still more situations as sufficiently like something in our past experience to be met in the same way. The moral code, the legal code, and any kind of general rules or principles are only possible because of this tendency. But how and why do our minds come to behave in this way? It is due in the beginning to the fact that we perceive incompletely, and quickly forget even the greater part of what we perceive. Consequently situations that are not alike look alike to us, through our not noticing their points of difference. Some kinds of similarity, as has been noticed earlier in this paper, will set off habitual or instinctive tendencies to respond, without the interference of conscious volition, or even in defiance of it. These give us the pure "functioning of identical elements" which has been so widely held to be the sole explanation of apparent transfer: the elements may not be objectively identical, but they are subjectively so. But as our observation becomes more accurate and our knowledge more extensive, we come to detect differences in situations that once looked alike, and where we once through ignorance treated situations as wholly identical, we now for convenience treat them as in some degree identical, though recognizing them as different. Thus we have the genesis of analogy, the principle which lies at the bottom of all thought, and without which all learning would be worthless, because without it we could not bring what we learn today to bear on the new situations which we have to meet tomorrow. The syllogism, that once supposed instrument of exact thinking and of certainty, is only a formula for reducing analogy to its lowest terms. All inference is transfer, and the transfer may be either of knowledge, as when we infer from the ratio between diameter and circumference of a circle in geometry to the ratio between the diameter and the circumference of the earth; or it may be transfer more strictly of training, as when 
we use the principles of construction learned in geometry, in building a house. These are cases of transfer between what we think of as closely related fields: but what we think of as related fields depends very much on custom and the state of our knowledge. Custom cannot create relationships, but it can blind us to those that exist. The relation between biology and psychology was scarcely recognized until after the middle of the last century: and every new application of science to practical life is the discovery of a new relationship, obvious enough when recognized, perhaps, but long unthought-of.

All transfer, then, is accomplished through the recognition of similarity in difference: that is, through analogy. All effective transfer is based on recognition of fundamental similarities, and on making correct adaptations to the accompanying differences. This requires patient, careful thinking, and a sound knowledge of the fields or facts which are brought into relationship. There are relationships everywhere: it is our business to find them, and also not to be deceived by superficial analogies. The type of thinking in philosophy, to take an example, is essentially the same as that used in working out a new hypothesis from experimental studies in science: but few philosophers would, in attempting to transfer their training to the field of science, take care to notice also the differences, and adapt themselves to their new data; and we might name scientists who have been equally unintelligent on their part, and made of themselves bad amateur philosophers. Again, "History repeats itself" - that is, Greek and Roman history, or any other, as well as our own, is full of instructive analogies, but they lie deep down; almost invariably, those who go to history for proofs and illustrations, fix on superficial analogies which neither prove nor illustrate. Analogy, then, is the one sole medium of thought and of transfer, but analogy may go wrong: we have yet to speak of the power through whose action analogy is made to go right.

II: The Constructive Imagination. When one turns from action and perception to thought, he retires to a world of his own, of images and concepts-he commits a sort of retreat from reality. The value of this human ability to substitute thinking-manipulation of concepts and images-for manipulation of things, cannot be overestimated; but it brings us to a halt before the paradox which it involves. To think, we must turn away from objective reality: to discover truth, either new or old, by our thinking, we must keep in constant and continuous touch with objective reality. One whose thought retreats from reality and stays in its retreat, may 
become a dialectician, a clever juggler of words and concepts, but he never will become a fruitful thinker even in a small way. All unquestioning acceptance of authority ,and reasoning from it, no matter how true the authority may be, commits this error; for such reasoning is not based on life, and consequently the reasoner himself cannot properly understand what either he or his authority says. It is always true that any great thinker's avowed followers are his worst enemies.

To correct this tendency of thought to become unreal, is the function of the imagination, which I define as the power of mind that brings thought into rapport with reality. Its one dominant characteristic is unswerving fidelity to essential truth: it leaps straight to the significance of what it contemplates; it catches the spirit of facts and events. Ribot, though his treatment of the imagination differs in many respects from that suggested here, notes clearly the principle underlying this. He says of the imagination: "It reveals a power superior to the conscious individual, strange to him although acting through him: a state which many inventors have expressed in the words, "I counted for nothing in that," " $(20$, p. 52$)$. And again, "the moment of inspiration is ruled by a perfect and spontaneous unity: its impersonality approaches that of the forces of nature," (20, p. 86). Ribot is speaking rather of the moment of inspiration in genius: but the same experience comes to all of us, but on a smaller scale, and often unnoticed, because taken for granted. We turn to this impersonal inspiration for truth, because the unconscious never lies: if it did, we should have what Plato calls " the lie in the soul." If we enlist the unconscious in our thinking, and preserve unperverted our ability to read its deliveries, we have truth in our grasp.

To make good our definition of imagination, we must keep the distinction made by Coleridge between imagination and fancy. Fancy is of two kinds: the first kind is simply imagination at play, and produces in literature such works as the "Arabian Nights"; while in dealing with the outside world it may be credited with the creation of caricatures, fantastic designs and structures made for amusement's sake, and our various games. Unlike imagination proper, it is not serious in what it does: and it never forgets the fact. The other kind of fancy results from an attempt to eke out a small bit of imagination by conscious effort, and make it larger: from it flow the group of faults in literature which Ruskin called "the pathetic fallacy"; and in science and philosophy the fault of which amateur and professional students alike are often guilty, of twisting facts to fit theories. We notice that 
fancy is not a separate power of mind, but is only either adulterated imagination, or imagination in sportive mood. Only to avoid confusion is it desirable to confine the term imagination to those uses of the faculty which are both serious and sincere.

The imagination is the only power through which new truth, and true analogies, can be discovered. It required a sustained effort of the imagination to give Darwin's data sufficient reality in his mind to suggest the conclusions in the "Origin of Species": it required a no less real, though smaller effort of the imagination to effect a right transfer of knowledge from geometry to house-building, or motor habits from baseball to tennis. Without imagination there may be transfer, but only by accident will it be advantageous. Imagination is the eye of the mind: without it, we proceed blindly. To use another figure, it works with our knowledge like Ezekiel preaching to the dry bones in the desert, when in response to his preaching the bones came together, were clothed with flesh, and became men once more.

The imagination is not subject to the will: we cannot command our moments of inspiration, be they great or small; but we can do so indirectly, by fulfilling certain conditions without which these insights will not come, and then waiting. The first of these conditions is that we saturate ourselves as far as our situation allows, with the kind of knowledge concerning which we are seeking insights; not only because we need the knowledge as material, but because we need the assurance of our own sincerity. The second condition is that we submit to the impersonality which we have already noticed as a trait of imagination. Unless we are willing to follow the truth where it leads, instead of coercing it to lead where we wish to go, the insights which do come will be lost on us. A third condition is a variant of the second: we must not try to strait-jacket our thinking into conventional forms. Forms, though useful, are dead, and moulded on the old. Thought will not always fit the mould, and must be free to take new forms.

To sum up briefly: all learning from experience, all thinking, all inference, is transfer: there are only differences in degree. Knowledge and habits may function as identical elements-transfer in a sort of reflex way-or they may be deliberately transferred, applied, through the discovery by intelligence of analogies, and adaptation to new uses. Analogy is the one and only medium of such transfer: imagination is the power through which true analogies are to be found, and advantageous transfers effected. 


\section{Practical}

It is commonly supposed that the doctrine of formal discipline has much to do with the selection of school subjects, and little to do with methods of teaching. Certainly many a pedagogical sin has been committed in its name, in the last half-century: many a fruitful reform has been opposed, many a school subject has been maintained in an unfruitful form, lest "disciplinary values" be lost. But if we take Locke's position as representative for the doctrine of formal discipline, these pedagogical sins are to be regarded as perversions grafted onto the doctrine by those who misunderstood it, by those who had a genuine respect and enthusiasm for culture, but were unable to express more correctly its educational basis; and by those, far less numerous, who had "axes to grind," and used the first instrument that came handy. To increase the confusion, other perversions have been mistakenly attributed to the adherents of the doctrine, by their opponents in controversy. If these perversions are taken as representative of the doctrine of formal discipline, then the trend of this paper is away from that doctrine; but if we take the positions of Montaigne, Locke, Herder, as representative, then the theories here advanced are in direct line of descent.

Passing to the practical suggestions that follow from the theories of this paper, they fall into two groups: those having to do with the curriculum, and those having to do with methods of teaching:

I. Principles of teaching. If what we teach is to have any transfer-value-which is almost equivalent to saying, if it is to have any practical value-for the average student, the transfer should be half-made in school. To make the transfer complete is to defeat the purpose of the school, which is to present experience in concentrated form, ready to be expanded and applied in later life: not to make any transfer at all in the school, results in blinding the pupils to the possibility of transfer-in closing their minds to the idea that theories and knowledge learned in school have any bearing on every-day life. The school-subjects, then, should, as Dewey urged, be related to life. Pupils in school must learn many things which cannot be based on their present experience, but a basis in their present experience should be sought wherever possible. A student who has analyzed a bit of his own thinking, will begin to see what logic is all about: one who has studied the growth of plants in his garden, or in the woods, is ready to understand botany. We cannot, as Plato imagined, dispense with the stars and yet study astron- 
omy. This relating of subjects to life is not to be secured merely by getting out text-books whose problems and discussions rest on the life of the immediate neighborhood. These will help, but a child can quite easily fail to recognize his own father's farm when he finds it in a text-book, as many of our teachers handle a text-book. The farm-wagon will look like Hector's chariot, after it has gone through the mill of the five formal steps. If the teacher is to relate to life the knowledge which he imparts to his pupils, it must be related to life in his own mind. A teacher of Shakespeare who is himself ignorant of and uninterested in human nature, may produce a few philologists or rhetoricians, but he will never make literature a force in the thought and life of his pupils, which is certainly the sole purpose of teaching literature in the high school. A teacher of physics who would make his pupils more intelligent and efficient in every-day affairs, must himself be awake to the countless illustrations and applications to be encountered everywhere, of the knowledge which he has to teach. We can only teach what we know: if we would teach anyone the uses of the knowledge which we have to impart, we must understand those uses, ourselves.

Since the two great media of transfer are intelligence and imagination, formalism in education is fatal to transfer. Formalism deadens both intelligence and imagination. Instead of encouraging the mind to use all the resources at its command in dealing with material both new and old, it insists that thought shall follow only certain prescribed channels, in a certain prescribed way. This ignores the fact that the best thinking is based on the richest variety of spontaneous suggestions, and the best mind is most fertile in ideas. Thought must have forms, to keep it from straying aimlessly, but these forms exist only for the sake of thought, and it should be free to remake them as it goes along. To condemn a student's work as "wrong" because it is not cast in what the teacher considers the orthodox forms, is utterly unpedagogical. Formlessness is to be condemned, but so long as the student's work is systematic, the forms which he uses may be judged as well or ill-aadpted to his work, and criticized accordingly, but they cannot properly be called simply "right" or "wrong." Where a superintendent commands his principals and supervisors, the principals and supervisors command the teachers, and the teachers obediently command the pupils, that every piece of work must be done in just one minutely prescribed way and no other: there we have the last word in unreality. It makes a fine machine 
for exhibition purposes, enables the superintendent to make a beautifully systematized report, and satisfies a certain ideal of mechanical efficiency-but what of the children? Accustomed only to strict obedience, not permitted to follow out their own intellectual tendencies, carefully guarded against the chance to meet intellectual difficulties at first hand-lest they meet them in a way which the teacher disapprovesthey are less able to think independently than if they had never been to school; and one who does not think independently, does not think at all. And no thinking, no transfer. The arithmetic learned in school will not be used more than absolute necessity compels; the history will have no influence whatever on the child as a future citizen; the hygiene course will not lead him to care more intelligently for sanitary conditions at home.

The effect of formalism on the imagination is even more serious. Imagination is the most elusive function of consciousness, and only perfect sincerity can induce it to speak, or enable us to hear correctly when it does speak. Formalism attempts to force into artificial and arbitrary channels the one function whose very nature is spontaneity-and imagination will not be coerced. It is well known that children who have been taught to draw, with rule and compass, as it were, in the Kindergarten, show much less artistic merit in their drawings than children of the same age who have not had such training. Any teacher who has tried to make English, or Latin, or geometry, or even botany, live in his pupils' minds, must have been oppressed by the utter inability of their imaginations after eight or nine years of schooling, to seize the meaning of a fact presented in the school-room. The imagination can be touched even then; many a live teacher succeeds in touching it, by making forms only ancillary, and by keeping fresh his own realization of the meaning of what he is teaching: but when a mind has been eingestellt against any hint of imagination in school work for years, it is no easy matter to break through the Einstellung, and the slightest provocation will restore it to dominance.

Vitality is not the only need in school work: it should also be difficult. This fact demands emphasis because it is a popular fallacy that work to be "interesting" must be sugarcoated, made easy, that the disagreeable must be tabooed: and perhaps some readers might imply that this plea for imagination in teaching involves the same thing. Not at all. One who has in his school career never done anything disagreeable, who has never had to study until he has gained his "second breath," has missed one of the most valuable 
results of an education. All the studies of the learning process, as well as universal experience, prove that it is hard and intense work that educates. But there are abundant difficulties in the nature of any subject, without arbitrarily imposing others; and these natural difficulties have the merit of stimulating thought and stirring imagination, while difficulties which the student feels to be arbitrarily imposed, are deadening, and tend to make most of the class feel that thinking is not an important part of education, while they repel the sturdier minds, and compel at best but a sullen acquiescence. Difficulties which are attacked unwillingly, under compulsion, only make the student more dependent on his taskmaster: he tends to lose all ability to set himself tasks and carry them out on his own initiative. But adolescents-as, indeed, most human beings-enjoy facing difficulties that are felt to be worth while, and mastering them. In such difficulties alone is disciplinary value to be found. For this reason, I might pause to add, studies should be prescribed only as a last resort. One works better at a study which he has chosen of his own free will. We must, apparently, in the present state of secondary education, have a large amount of prescription, but it should be recognized for what it is-a necessary evil-and mitigated in every way possible.

II. The Curriculum. Since transfer is possible, and, given sensible teaching, is assured: therefore we may lay it down as a first principle in deciding on educational values, that those subjects whose content is of the widest applicability, are the first to be chosen, where general education is the aim. Also, even in strictly vocational training, the wider applicability of the principles underlying the rules of the trade, should be brought to notice wherever possible. This gives a better control over the rules of the trade itself, has a great cultural value as a stimulus to thought, and most important of all, perhaps, gives the one so educated greater adaptability. In the rapidly changing industrial conditions of the time, no one can foresee with certainty the future of any trade. New inventions, new methods, may make one's training an unsalable article when he has barely finished his apprenticeship; and the more highly specialized his skill, the less adaptable will he be to new conditions, unless he has also kept open avenues of transfer of training, through basing his knowledge and training on general principles, and avoiding the formation of a too rigid set.

It follows from this that pure science is preferable to applied science. Really, pure science should in its teaching 
methods approximate to applied science, since, as said before, the transfer from theory to practice should be half-made in school. But the point of view should be that of pure science, which concerns itself about general principles, and the relations between them: not that of applied science, which only lays down rules for the performance of certain acts, and cares not at all why those rules hold good. An empirical formula is a block of offense to pure mathematics; to applied mathematics, one formula is as good as another, if it works. In teaching pure science, the pupil will best understand these general principles if he has arrived at some of them by his own observation: therefore the first approach to a science should be inductive, free from any special apparatus, and innocent of technical terminology. The average boy would stand in awe of a dollar watch if he saw it labelled a chronometer, in a laboratory. The first two or three weeks of a physics course, for example, should be done without either text-books or laboratory; the students should simply be set to studying intently the behavior of familiar things, until they had firmly grasped a few fundamental principles. It would be even better to give this preliminary work, or some of it, at least, in the last week or two of the year preceding the physics course itself, so as to give the pupils something to think about during the summer. In this way the long vacation, which is now very much a period of forgetting, would become a period of learning-of learning of the best kind. Given this informal introduction to the science, then the technical names for the principles that have been observed, can safely be given, and the work with text-book and laboratory begun. To do all the work inductively would gain nothing, and would slow up the course intolerably; but a week of inductive study at the beginning will give a basis of understanding from which the pupils will be able spontaneously to apply their knowledge in understanding and dealing with all sorts of everyday problems, as fast as the knowledge is acquired. They have started out with a "transfer-Einstellung," so to speak, and will work over their knowledge as they go along: without this Einstellung, their knowledge remains isolated, and every bit of it that is to be used must be worked over anew, later. Further, this isolation develops a feeling of unreality which is one of the hardest of all mental sets to break up.

A second determining principle in planning a curriculum, is that the student's course of study should contain several different kinds of subjects. The mind will form sets, especially in adolescence, whether we wish it or not; the school 
should see to it that a sufficient number and variety of sets should be formed, so that the student is reasonably wellequipped on other sides of his nature, as well as on the side that his future vocation will develop. This is needed not only for his own personal good, but also because every man is a citizen and a member of society, as well as a workman. $\mathrm{He}$ is a layman with respect to every vocation but one, and on the intelligent interest of the layman depends practically all progress in every line. Without the pressure of that intelligent interest upon them, professionals in any line become stereotyped, averse to change, and resist improvements that the thoughtful members of their body suggest.

A third principle is that every one's course of study should be so chosen that the different subjects will supplement each other in the kind of work provided. The student should be allowed and induced to do his own choosing, so far as practicable, but in any case, the choice should heed this principle. Every subject has its characteristic effect on the mind, both for good and bad. The effect of geometry as put in the passage from Pascal quoted above, will serve as an example. The course of study should be planned to make these characteristic effects balance each other. Moreover, every subject makes some demand on powers which, because that demand in the given subject is slight and scattered, it fails to develop adequately. Thus, to take an example from advanced study, biology demands, to evaluate its data, precisely the kind of thinking which is the characteristic feature of philosophical study, and it has also to deal at times with conceptions which are central in philosophy. But in the study of biology, this kind of thinking and these conceptions play so small a part, quantitatively speaking, that the biologist acquires little familiarity with them, in his study, and often betrays a surprising incapacity when he has to deal with them; and with it sometimes an equally surprising blindness to his own incapacity. An intelligent study of philosophy-which must also be a sympathetic, interested study of it-would at the same time soften the arrogance and correct the incapacity. The same thing applies, mutatis mutandis, to every study. Every specialist, from philosopher to classicist, is likely to be arrogant in his claims, and to be handicapped in his own line through lack of some kind of knowledge and training which is needed, but not adequately provided, in specialized study.

Finally, the school should aim to teach a few things well and thoroughly to each student, not to give a scattering knowledge of a great variety of subjects. Not content, but assimilable content, is what counts in education, and before 
knowledge can be assimilated, there must be present in the mind a coherent body of related knowledge. A well and broadly-educated adult can assimilate almost any bit of knowledge in almost any form, with some success; but an adolescent, whose education is only beginning, must have enough of a given study presented to develop it into coherence. If insufficient time is given to the study, nothing is likely to be gained from it but a chaos of mere memorized facts, useless, because unassimilated. Given a nucleus of three or four principal studies, little excursions into other lines are valuable as means of starting centers of apperception, some of which, at least, may be followed up independently later; and as a means of helping the pupils to see how wide and rich the life of the world is. But the work should not all be little excursions, and the excursions themselves should be given by methods less formal than the studies which are especially stressed: set study should fall into the background, there should even be no final grades, no academic ranking, on such work. While such work may have immense potential value, it has no present academic value of the kind which credits should represent, and we only deceive ourselves by pretending that it has. Besides, "working for marks" always diminishes spontaneity, and makes teacher and pupil in a sense natural antagonists: we should welcome the opportunity to abolish marks wherever possible. Thus academic ethics and pedagogic efficiency demand the same thing.

But returning to the point that the students' course should consist mainly in intensive and thorough study of a few subjects: another reason for this is that the preliminary stages of any study are almost purely memory-work, and to get any disciplinary value, or any cultural value, the work must be carried beyond that stage, to the point of a certain degree of mastery. Anyone would recognize that one who has learned to play the piano well is better trained musically than one who has spread his time over the study of twenty or thirty instruments, can play the scale on all, but can do nothing else on any. The latter has spent all his time on elementary details of technique: the former has been able to live and study on planes of musical significance of which the other has no knowledge. We recognize this in music, but in school-study it is overlooked. Even on the well-established principle of the hierarchy of habits, the second year of a subject should have more cultural value than the first; the third than the second. It should be recognized, and never forgotten, that higher mental habits are more generic, are more readily transferable, than lower; and that the fact of 
having worked through all or nearly all the stages of the learning process in any one subject, furnishes a basis of guidance in attacking any subject, which basis is often sufficient to cut years off the time required for a new subject.

\section{BiBLIOGRAPHY}

I. Adamson, J. W. John Locke's educational writings. London, Arnold, I912. 265p.

2. Bagley, W. C. Educational values. N. Y., Macmillan, I9II. 267p.

3. Comenius, J. A. The Great Didactic. London, Black, I89I. $468 \mathrm{p}$.

4. Coover, J. E. \& Angent, F. General practice effect of special exercise. Am. Jour. of Psychol., 1907, Vol. I8, pp. 328-340.

5. Davidson, T. Rousseau and education according to nature. N. Y., Scribner, I895. 268p.

6. De Garmo, C. Herbart and the Herbartians. N. Y., Scribner, I895. 268p.

7. Dewey, John. How we think. Boston, Heath, I9io. 224p.

8. _- School and society. Chicago, Univ. Press, 1899. I25p.

9. FRACKER, G. C. On the transference of training in memory. Psychol. Rev. Mon., I908, Vol. 9, No. 38. Univ. of Iowa Studies in Psychol., No. 5, pp. 89-93.

io. Graves, F. P. History of education during the middle ages and the transition to modern times. N. Y., Macmillan, 1912. 328p.

II. Hart, B. and Spearman, C. General ability, its existence and nature. Brit. Jour. of Psychol., I9I2, Vol. 5, pp. 5I-84.

12. Heck, W. A. Mental discipline and educational values. N. Y. Lane, I9II, 208p.

13. Henderson, E. N. Textbook in the principles of education. N. Y., Macmillan, I910. 578p.

I4. - Formal discipline. Monroe's Cyclopedia of Education. N. Y., Macmillan, I9II, Vol. 2, pp. 642-3.

15. JUDD, C. H. Special training and general intelligence. Ed. Rev., 1908, Vol. 36, pp. 28-42.

I6. MONROE, P. History of education. N. Y., Macmillan, 1905. 772p.

I7. _ Sourcebook of the history of education for the Greek and Roman period. N. Y., Macmillan, 1901. 505p.

i8. Montaigne, M. E. Education of children. N. Y., Appleton, 1899. I52p.

19. Meumann, E. The psychology of learning. Trans. by J. W. Baird. N. Y., Appletons, I9r3. 393p.

20. Ribot, T. Essay on the creative imagination. Chicago, Open Court Pub. Co., I906. 370p.

2I. RoYCE, J. Outlines of psychology. N. Y., Macmillan, I903. $392 p$.

22. RUEDIGER, - Principles of education. Boston, Houghton Mifflin, 1910. 305p.

23. Ruger, H. A. The psychology of efficiency. Archives of Psychology, 1910, No. 15. 88p.

24. Steight, W. G. Memory and formal training. Brit. Jour. of Psychol., I9II, Vol. 4, pp. 386-457.

25. SPEARman, C. Qualified and unqualified "formal training." Jour. of Exp. Pedagogy, I9I4, Vol. 3, pp. 247-54.

26. THORNDIKE, E. L. Educational psychology. N. Y.; Teachers College, 1914, Vol. 2. 
27. - and WOODWORTH, R. S. The influence of improvement in one mental function upon the efficiency of other functions. Psychological Rev., I90r, Vol. 8, pp. 247-26r ; 384-395; 553-564. 28. Woodward, W. H. Vittorino da Feltre. Cambridge, Univ. Press, 1897. 250p.

29. - Studies in education during the age of the Renaissance. Cambridge, Univ. Press, 1906. 336p.

30. Ziegler, T. Geschichte der Pädagogik. Munich, Bcck, 1909. 4rop. 

THIS BOOK IS DUE ON THE LAST DATE STAMPED BELOW

AN INITIAL FINE OF 25 CENTS WILL BE ASSESSED FOR FAILURE TO RETURN THIS BOOK ON THE DATE DUE. THE PENALTY WILL INCREASE TO 50 CENTS ON THE FOURTH DAY AND TO \$1.00 ON THE SEVENTH DAY OVERDUE.

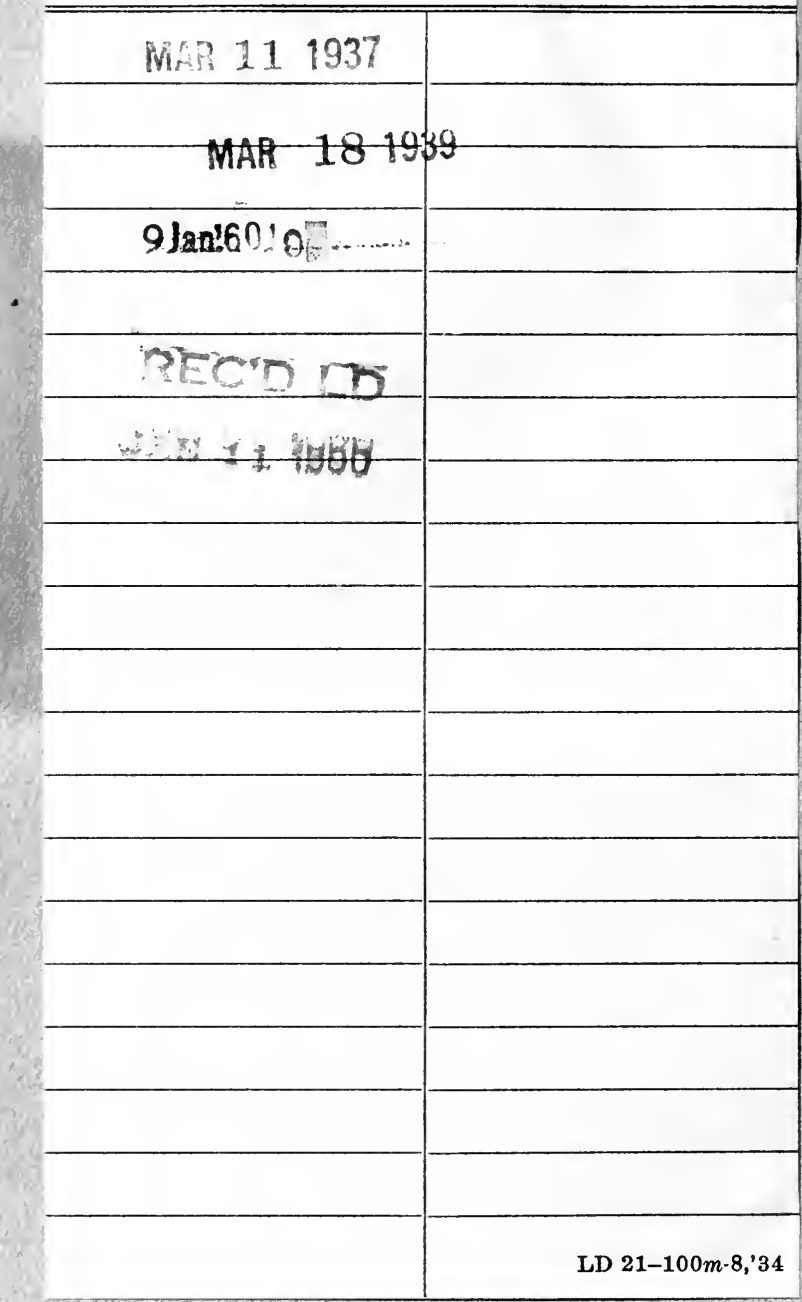




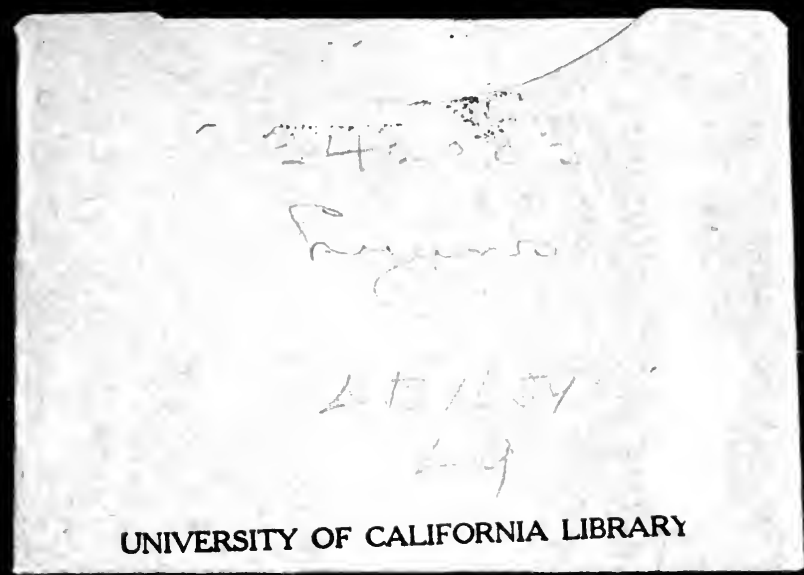




\section{s.

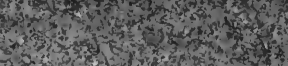

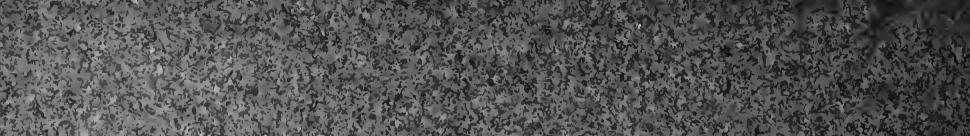
(6) $\begin{array}{lll} & \end{array}$ $\begin{array}{lll} & \end{array}$ $\begin{array}{lll} & \end{array}$

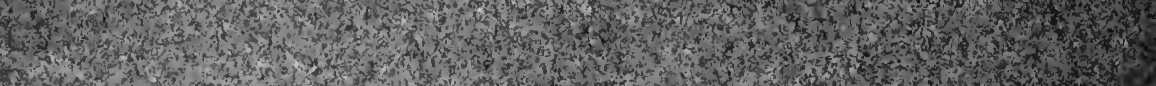

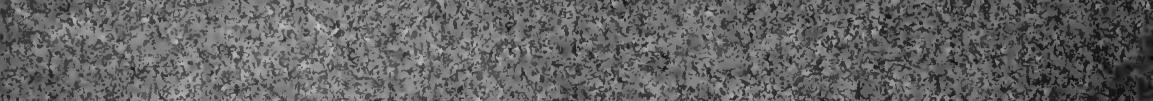

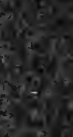
3
3

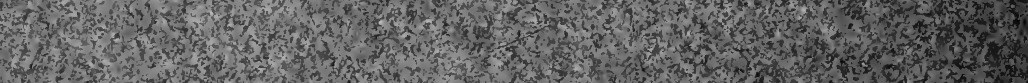

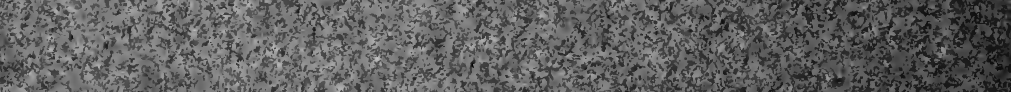

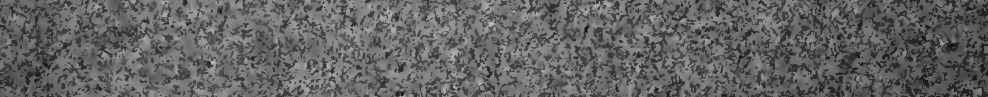

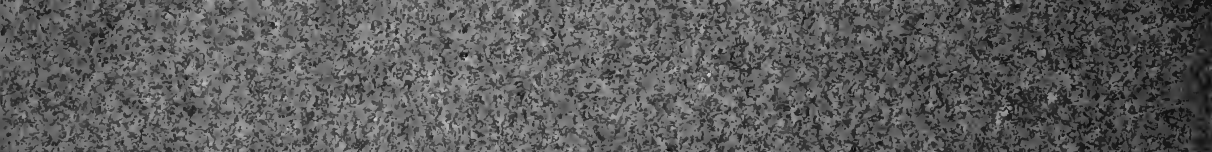

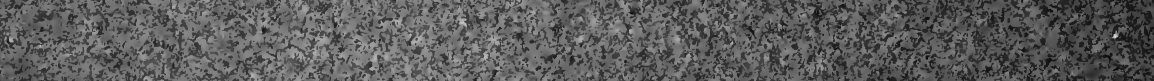

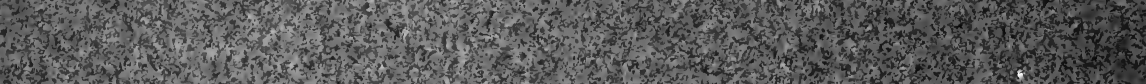

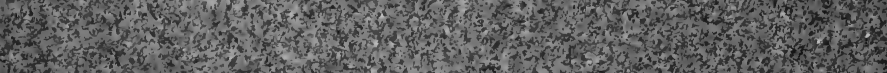

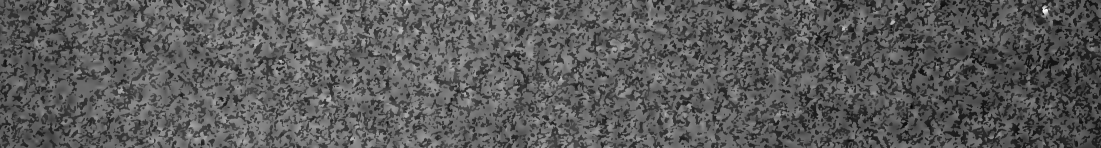

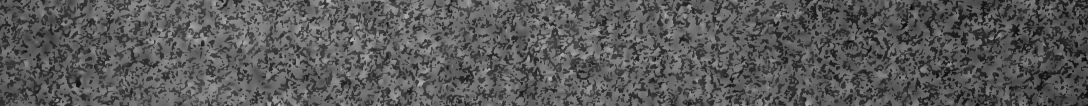

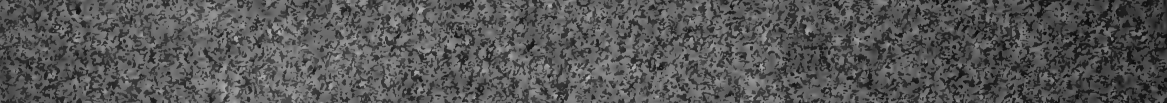

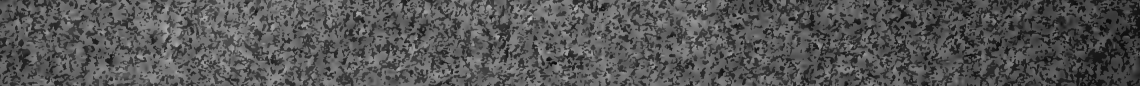

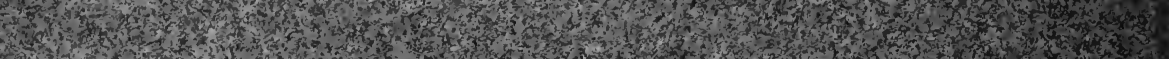

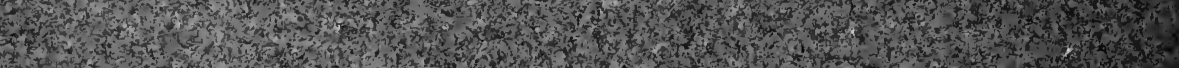

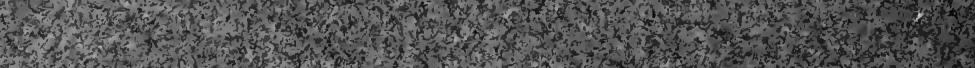
3.7.

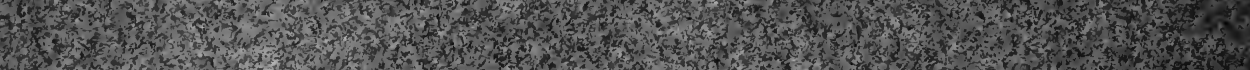

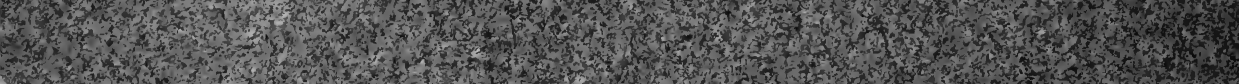

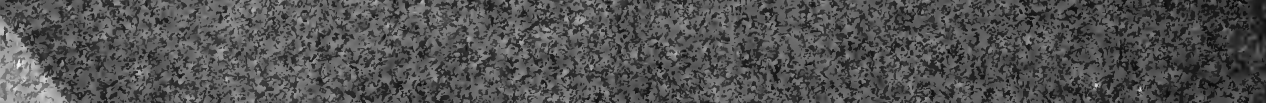

